\title{
Dinero, poder y política: financiamiento electoral como clave en la influencia de Odebrecht en Perú y México
}

\author{
Money, power and politics: electoral financing as key in the \\ influence of Odebrecht in Peru and Mexico
}

\section{Kenyi Martinez Encarnación (*) Pontificia Universidad Católica del Perú ORCID: 0000-0003-1349-1593}

Fecha de recepción: 21 de mayo

Fecha de aceptación: 5 de agosto

\section{ISSN en línea: 2415-248}

Martínez Encarnación, K. (2019) «Dinero, poder y política: financiamiento electoral como clave en la influencia de Odebrecht en Perú y México». Politai: Revista de Ciencia Política, Año 10, primer semestre, No18: pp. 128-168.

DOI: https://doi.org/10.18800/politai.201901.005

\footnotetext{
* Estudiante de Ciencia Política y Gobierno en la Pontificia Universidad Católica del Perú. Ha sido ponente en el "IV Congreso Internacional Estudiantil de Derecho Administrativo", organizado por la facultad de Derecho de la UNAM en el Instituto Nacional de Administración Pública- Ciudad de México.
} 


\section{Sumilla}

En la actualidad, Odebrecht es el caso más emblemático de corrupción en América Latina, involucrando a decenas de políticos, empresarios y obras públicas de países como Perú y México. Sin embargo, el problema no solo se trata de corrupción, sino que detrás hay un sistema poco conocido, donde la preocupación tiene que ver con las “reglas de juego” y sus “jugadores”. Por ello, este artículo pretende explicar por qué Odebrecht pudo influir en las decisiones de los Estados peruano y mexicano para adjudicarse contrataciones públicas. En esa línea, se sostiene que fueron por tres razones. En primer lugar, su entrega oportuna era atractiva para los políticos, porque tenían eficacia para terminar las obras antes de que acaben su mandato; y por ende, puedan inaugurarlas con un incentivo adicional ("lado bueno de la empresa”). En segundo lugar, otro factor fue su influencia en el Estado, porque crearon una red de corrupción con las esferas más altas de Gobierno a través del financiamiento electoral, sobornos, lobbies y constructoras locales para ganar licitaciones ("lado oscuro de la empresa”). El financiamiento electoral resulta clave, porque creaba las bases para luego armar una red peligrosa a fin de buscar más poder en la política a través del dinero. En tercer lugar, un último factor fue la debilidad institucional, porque la firma brasileña aprovechó un contexto de leyes "sastres", que no solo evitaban fiscalizaciones y rendición de cuentas, sino que facilitaba la corrupción como si fuesen hechas a las medidas del "cliente". Finalmente, se explican estos tres factores a partir de dos megaproyectos en Perú y México: Metro de Lima Línea 1 y Refinería Miguel Hidalgo Tula I.

Palabras clave: Odebrecht, líderes políticos, acuerdos, corrupción, financiamiento electoral, entrega oportuna, influencia en el Estado y debilidad institucional. 


\begin{abstract}
Currently, Odebrecht is the most emblematic case of corruption in Latin America, involving dozens of politicians, businessmen and public works, including Peru and Mexico. However, the problem is not only about corruption, but it is behind a little known system, where the concern has to do with the "rules of the game" and their "players". Therefore, this article aims to explain why Odebrecht was able to influence Peruvian and Mexican states' decisions about awarding public contracts. In that line, it is argued that they were for three reasons. First, their timely delivery was attractive to politicians, because they were effective in finishing the works before they finished their term; and, therefore, they can inaugurate them with an additional incentive ("good side of the company"). Second, another factor was its influence on the State, because they created a corruption net with the highest levels of government through electoral financing, bribes, lobbies and local constructions to win tenders ("dark side of the company"). In particular, electoral financing was key, because it creates the basis for later building a dangerous network in order to seek more power in politics through money. Third, a final factor was institutional weakness, because the Brazilian firm took advantage of a context of "tailor" laws that not only avoided audits and accountability, but also facilitated corruption as if they were made to the measures of the "client ". Finally, it explains these three factors from two megaprojects in Peru and Mexico: Metro de Lima Line 1 and Miguel Hidalgo Tula I Refinery.
\end{abstract}

Keywords: Odebrecht, political leaders, agreements, corruption, electoral financing, timely delivery, influence on the State and institutional weakness. 


\section{Introducción}

En la actualidad, Odebrecht es el caso más emblemático de corrupción en América Latina. De hecho, en marzo del 2014, un caso de gran repercusión mediática y política como Lava Jato estalló en Brasil y casi de inmediato involucraría a decenas de políticos latinoamericanos, incluso hasta África. Posteriormente, en el 2015, Marcelo Odebrecht reveló que había expandido su negocio a través de una compleja red de corrupción entre sobornos, sobrecostos y financiamiento de campañas para obtener beneficios en contrataciones públicas, entre ellos Perú y México. Sin embargo, el problema no solo trata de corrupción, sino que detrás hay todo un sistema que la facilita: "captura corporativa estatal”. En esa línea, este problema no se trata de cuestiones ideológicas, sino que la preocupación tiene que ver con "las reglas de juego" y sus "jugadores” (el que ofrece, el que recibe y el que fiscaliza).

Por ello, el presente artículo pretende explicar por qué Odebrecht pudo influir en las decisiones del Estado peruano y mexicano para adjudicarse contrataciones públicas, es decir, por qué la firma brasileña influyó para ganar licitaciones en dos países con altos índices de corrupción, pero con diseños estatales diferentes: unitario y federal. En esa línea, se propone que hubo un acuerdo entre la firma brasileña y los líderes políticos para influir ventajosamente en sus países, donde la constructora gané licitaciones por tres razones (entrega oportuna, influencia en el Estado y debilidad institucional) a partir de dos megaproyectos en Perú y México: Metro de Lima Linea 1 y Refinería Miguel Hidalgo Tula I.

El presente estudio se divide en cinco secciones. En primer lugar, se presenta una breve revisión de la literatura acerca de captura corporativa estatal en países latinoamericanos. En segundo lugar, se definen algunos conceptos básicos como punto central de la investigación. En tercer lugar, a partir del caso Odebrecht, se explican tres factores que configuran su sistema de "conquista": entrega oportuna, influencia en el Estado y debilidad institucional. En cuarto lugar, se comparan estos tres factores a partir de dos casos representativos de su modus operandi en Perú y México: Metro de Lima Linea 1 y Refinería Miguel Hidalgo Tula I. Finalmente, se presentan las conclusiones sobre este fenómeno a partir de las investigaciones encontradas en ambos países, y se finaliza con algunas reflexiones sobre la relación entre dinero, poder y política.

\section{LA CAPTURA CORPORATIVA ESTATAL Y SUS VARIANTES}

La captura política es una forma de influencia extrema sobre el Estado para inclinar las decisiones a favor de unos cuantos privilegiados que concentran recursos, los cuales pueden ser élites económicas, élites políticas, partidos políticos e incluso familias (Durand 2010:10). Sin embargo, el presente trabajo se limita a realizar una breve revisión de la literatura sobre captura política por parte de actores corporativos, entendidas como élites económicas influyentes. Por ello, estudiar la relación empresaEstado, constituye un campo de estudio relevante, porque hay un creciente interés sobre cómo se maneja el poder entre las élites políticas y élites económicas para obtener beneficios mutuos, es decir, si hay un "acuerdo" establecido entre ambos actores para influir ventajosamente en el Estado a cambio de beneficios personales. En esa línea, se explican tres de sus variantes: 
Primero, autores como Stigler y Peltzman sostiene que la "captura regulatoria” es un tipo de fallo en una entidad reguladora para actuar a favor de ciertas empresas o grupos de interés como, por ejemplo, regulaciones "flojas" en beneficio de grandes firmas en sectores extractivos, energéticos, etc (1971 y 1976: 211-240). Es decir, es una relación de empresa- sector regulador, donde grandes corporaciones dotadas de recursos y conectadas políticamente influyen solo en las decisiones del ente que los regula a su favor ${ }^{1}$.

Segundo, autores como Hellman, Jones y Kaufmann sostienen que la "captura estatal” es una relación empresa-Estado, entendida como "influencias indebidas", porque las corporaciones recurren principalmente a la corrupción para armar una red estrecha con la élite política local, que les permita "capturar" funcionarios públicos a varios niveles del Estado (2000). Por ejemplo, las grandes firmas pueden diseñar estrategias a través de pagos de comisiones ilícitas (sobornos) para obtener beneficios indebidos. En breve, las empresas recurren principalmente a los mecanismos de corrupción para influir en el Estado $^{2}$.

Tercero, autores como Durand sostienen que este fenómeno va más allá de la corrupción: captura corporativa estatal como “influencia excesiva”. Por ello, argumenta que es una situación donde élites económicas y élites políticas dotadas de grandes recursos logran proyectarse ventajosamente en el Estado, quienes recurren a mecanismos que van más allá de la corrupción: financiación de campañas, lobbys en la sombra, "comprar" leyes, "puerta giratoria”, "alianzas" con otras empresas, incluso influencias en los medios de comunicación de masas y opinión pública ${ }^{3}$ (2010:12-16). Es decir, es una situación donde las corporaciones y líderes políticos hacen un "acuerdo" establecido para formar "influencias excesivas", y a veces indebidas, en las decisiones del Estado, porque recurren a mecanismos que varían entre lo legal, ilegal y dudoso a fin de obtener ventajas personales contrarias al desarrollo social, y, por ende, pueden poner en peligro a la democracia.

\section{MARCO TEÓRICO}

Para fines del presente trabajo, es importante definir algunos conceptos e identificar a los actores "captores" con sus mecanismos, porque indica quién arma la red, y cómo se benefician. En primer lugar, sobre captura corporativa estatal, se entiende como una situación donde se maneja el poder entre corporaciones, sean nacionales o extranjeras; y líderes políticos, sean caudillos, "salvadores de la patria” o partidos hegemónicos, para influir ventajosamente en el Estado a fin de obtener beneficios personales en contra del desarrollo social, usando una serie mecanismos legales, ilegales y dudosos (Durand 2010, Membreño 2007 y Omelyanchuk 2001). En esa línea, es una relación empresa-

\footnotetext{
1 De acuerdo a Stigler, las regulaciones solo se aprueban a favor de las grandes firmas. Ver George Stigler, "The Theory of Economic Regulation", Bell Journal of Economics and Management Science, $N^{\circ} 2$ (Spring 1971): 3-21. Ver también Sam Peltzman, "Toward a More General Theory of Regulation", Journal of Law and Economics, 19, N 2 (1976), pp. 211-240.

2 De acuerdo Hellman, Jones y Kaufmann, las grandes corporaciones influyen en el Estado, quienes recurren solamente a mecanismos de corrupción como sobornos o "coimas", Ver Hellman, Jones y Kaufmann, "Seize the State, Seize the Day: State Capture, Corruption and Influence in Transition", Washington DC: Banco Mundial, Policy Research Working Paper 2444, pp.1-39. http://siteresources.worldbank.org/INTABCDEWASHINGTON2000/Resources/hellman.pdf

3 De acuerdo con Durand y otros autores, los grandes actores económicos pueden embarcarse en capturar al Estado recurriendo a mecanismos legales e ilegales o combinándolos creativamente. Ver Cuando el poder extractivo captura el Estado: lobbies, puerta giratoria y paquetazo ambiental en el Perú, Lima, 2016, OXFAM, p.12-16.
} 
Estado, donde las corporaciones, dotadas de grandes recursos, pueden recurrir principalmente a la corrupción para armar una red estrecha con la élite política local, que les permita capturar funcionarios públicos a varios niveles del Estado: presidentes, ministros, parlamentarios, funcionarios públicos, etc (Hellman, Jones y Kaufmann 2000). Primero, pueden moldear el marco institucional, es decir, las reglas de “juego", para que puedan operar sin presiones. Segundo, diseñan estrategias a través de pagos de comisiones ilícitas para adjudicarse contrataciones públicas.

En segundo lugar, sobre el modelo de influencias Odebrecht, es un sistema de la firma brasileña con una serie de mecanismos legales, ilegales y dudosos- financiamiento de campañas, sobornos y lobbies- para mantener relaciones cercanas a largo plazo con una serie de personajes influyentes como presidentes, ministros, funcionarios, entre otros, a fin de evitar fiscalizaciones, regulaciones y trámites burocráticos (Durand 2018: 75-80). En especial, el financiamiento electoral es clave, porque significa la base del pacto con el político para luego armar la red de corrupción a niveles inferiores.

En tercer lugar, sobre corrupción, se entiende como el mal uso del poder empresarial, político y burocrático a fin de obtener mezquinos intereses privados en contra del desarrollo social través de una serie mecanismos que varían entre lo legal, ilegal y antiético (corrupción negra, gris y blanda) distorsionando las reglas que protegen los intereses públicos y a las entidades encargadas de luchar contra la corrupción (Quiroz 2013: 30-34). En esa línea, se trata de una situación enraizada en las estructuras sociales y ligada a una evolución institucional precaria que no ha podido detener comportamientos oportunistas, donde la preocupación tiene que ver con las "reglas de juego” y sus “jugadores” (el que da el soborno, el que lo recibe, y el encargado de combatirla). En consecuencia, las normas favorables al desarrollo son inexistentes, están distorsionadas o se muestran inestables; $y$, por ende, se producen sucesivas olas de corrupción.

Por último, sobre entidades públicas, como cualquier institución, se rigen por reglas del Derecho Administrativo y existen una serie de principios como, por ejemplo, eficacia y transparencia, de orden constitucional en las administraciones públicas que permiten conseguir un buen funcionamiento de los servicios públicos a la ciudadanía (Danos 2017, Jinesta 2009 y Rubio 2017). En ese sentido, para garantizar un ambiente de confianza entre las instituciones públicas y la sociedad, las normas que la rigen- leyes, decretos, etc- deben cumplir con dichos principios a fin de mejorar su funcionamiento, fortaleciendo a las entidades públicas con recursos normativos, técnicos y mayor autonomía para luchar contra la corrupción.

Asimismo, para fines del presente, se identifican los siguientes mecanismos utilizados por los actores “captores”- empresarios y políticos- que varían entre lo legal, ilegal y antiético ${ }^{4}$ :

1. Financiamiento de partidos es la base del pacto entre Marcelo Odebrecht y los líderes políticos para luego armar la red de corrupción en tres niveles (jefes, intermedios y decisores).

\footnotetext{
4 Estos mecanismos están vinculados a la "corrupción blanda" entendida como conductas oportunistas para obtener ventajas personales mediante prácticas "legales". Ver Arturo Del Castillo: "Medición de la corrupción: un indicador para la rendición de cuentas".
} 
2. Soborno es un arreglo ilegal entre una autoridad-funcionario público y el empresario mediante la entrega de dinero para ganar licitaciones.

3. Lobbys son personajes conectados políticamente para asegurar que las decisiones sean favorables para el acuerdo empresarios-políticos como si fuesen gestores de intereses.

4. Alianzas estratégicas con constructoras locales son relaciones colusivas para aprovechar sus conexiones políticas y penetrar ventajosamente en los mercados nacionales sin competencia a fin de que todos salgan ganando (repartición de obras).

5. Leyes "sastres" son normas que incentivan la conducta para facilitar la corrupción, evitando las fiscalizaciones y rendiciones de cuentas. Dicho de otra manera, son reglas que no garantizan un sistema de pesos y contrapesos, debilitando a los actores encargados de luchar contra la corrupción.

\section{ODEBRECHT Y SU SISTEMA DE “CONQUISTA”: TRES FACTORES}

Para fines del presente trabajo, la captura corporativa estatal es entendida como una situación donde se maneja el poder entre élites económicas y élites políticas para influir ventajosamente en el Estado a fin de obtener intereses personales en contra del desarrollo social, haciendo uso de una serie mecanismos legales, ilegales y dudosos. En esa línea, para desarrollar infraestructura nacional, este manejo de poder se expresa en arreglos o acuerdos entre los empresarios y los líderes políticos en cada país.

Por ello, en un contexto de construcción de obras, los principales actores son dos: grandes empresas constructoras y el Gobierno. Por un lado tenemos, a la gran constructora brasileña Odebrecht, la cual llegó a convertirse en la mejor empresa de construcción y símbolo de prestigio en América Latina; y por otro lado, a políticos y funcionarios de varios niveles de Gobierno, empezando por el presidente quien tiene la iniciativa de los megaproyectos, y terminando hasta el administrador público, que autoriza quién gana la licitación de la obra.

En esa línea, a continuación se desarrollan tres factores del modus operandi de Odebrecht para adjudicarse contrataciones públicas. Este debe ser entendido en un contexto de acuerdos establecidos entre ambos actores (empresarios y líderes políticos), es decir, se explican tres elementos de su sistema de “conquista” para ganar más obras.

\subsection{ENTREGA OPORTUNA: “OBRAS A TIEMPO”}

Un factor que influyó en la adjudicación a Odebrecht fue la entrega oportuna, porque esta empresa era eficaz para terminar las obras públicas antes de que los políticos acaben su mandato, a fin de que puedan inaugurarlas como un incentivo personal, pues les generaría redito político. En esa línea, uno de los pilares de Odebrecht que lo hizo especial en el mercado de la construcción era este tipo de entrega en el plazo solicitado por los presidentes, incluso podían entregarla antes, a fin de inaugurarla en medio de una alta presencia pública, porque los políticos tienen un interés especial para culminar las obras a fin de aumentar su capital político (Durand 2018:76). Dicho de otra manera, la constructora brasileña podía ofrecer las garantías a partir de las inauguraciones para que 
los políticos aumenten sus probabilidades de éxito en unas eventuales elecciones o simplemente dar seguridad a las inversiones del Gobierno como símbolo de "eficacia" durante su gestión política. En breve, la capacidad de entrega oportuna no solo daba la obra a tiempo, sino que ofrecía ciertas garantías a los intereses del Gobierno ${ }^{5}$, porque tenían el soporte financiero, prestigio y trayectoria empresarial como constructora para cumplir las obras en las fechas previstas.

Asimismo, la entrega oportuna de Odebrecht se basaba en una relación clientelar entre el político y el empresario. En ese sentido, la base de este sistema clientelista se encuentra en la acumulación por parte de los políticos y empresario de recursos necesarios para consolidar sus probabilidades de éxito, cada uno en su ámbito: por un lado, el político podría reducir la competencia en "el mercado político" para facilitar un triunfo electoral, ganando votos con la inauguración de obras; y por otro, el empresario puede reducir la competencia en el mercado concentrando cada vez más recursos económicos, incluso alcanzar una condición de privilegio o "monopolio" en el mercado de la construcción (Bresson 2010: 87-88). En efecto, estos recursos necesarios los podía ofrecer Odebrecht con la entrega oportuna para que ambos actores (Gobierno y empresa) se beneficien, porque así como el político puede ganar votos a partir de las inauguraciones de obras públicas, la empresa puede proyectarse internacionalmente en el mercado constructor a partir de la culminación de esta. En suma, la capacidad de entrega oportuna era símbolo de “eficacia” para el político y la constructora, donde había beneficios mutuos.

Por ejemplo, Odebrecht entregó el titánico Proyecto Olmos en Lambayeque- Perú, uno de los más difíciles del mundo por las condiciones de construcción. En esa línea, el 18 de noviembre del 2014, el presidente Ollanta Humala pudo inaugurar esta mega obra hidroenergética, la cual fue un emblema durante su gobierno, pero luego sería cuestionada por presuntos sobornos (El Comercio 2014).

No obstante, para lograr esa eficacia con la entrega oportuna, la habilidad de organización de Odebrecht era una condición importante. De hecho, a medida que Odebrecht se fue formando como empresa de ingeniería pesada fue perfeccionando sus relaciones internas para mejorar su organización y ofrecer servicios que le permitan lograr la internacionalización. En ese sentido, en 1981, Norberto Odebrecht empezó a desarrollar proyectos de cambio organizacional y publicó el libro "Sobrevivir, crecer y perpetuar: tecnología empresarial Odebrecht (TEO)” como una representación para desarrollar su modelo de negocios, porque proyectaba una idea de transformación interna a partir de una estructura jerárquica y descentralizada para convencer a sus gerentes y empleados en creer y perseguir la misión basada en tres verbos del libro: “sobrevivir, crecer y perpetuar” (Norberto 2011: 5-6). Asimismo, Durand sostiene que la finalidad del libro era servir a sus clientes, es decir, los gobiernos, empresas y accionistas, porque se había creado una división de trabajo entre gerentes y trabajadores para generar ganancias para sus clientes y, en especial, a los Gobiernos y a los accionistas, que eran principalmente los miembros de la familia Odebrecht (2018: 7071). En breve, la entrega oportuna de Odebrecht se basaba en la habilidad de

5 La entrega oportuna de servicios era clave para el modelo de negocios de Odebrecht a fin de perfeccionar sus relaciones externas con sus clientes, políticos, funcionarios, entre otros stakeholders. Ver también Francisco, Durand, Odebrecht: la empresa que capturaba gobiernos, Perú, PUCP, 2018, pp. 76-77 
organización interna para ofrecer servicios que satisfagan a sus clientes, entre ellos los Gobiernos y presidentes ${ }^{6}$

En consecuencia, al perfeccionar sus relaciones internas para internacionalizarse, la entrega oportuna era atractiva para los Gobiernos. De hecho, la Tecnología Empresarial de Odebrecht (TEO) no solo sirvió como inspiración para la internacionalización para hacer más obras, sino que se convirtió en un "atractivo" para muchos presidentes por su eficiencia para terminar obras lo más rápido posible e inaugurarlas. En ese sentido, la TEO reflejó la maduración de la constructora para internacionalizarse y servir de “capital político”, porque no solo llegaron a convertirse en la mayor empresa de ingeniería y construcción de América Latina, sino que era la mayor exportadora de servicios de ingeniería brasileña, donde hicieron decenas de obras para presidentes de Brasil, Perú, etc (Zebinden, Oliva y Gaspar 2007: 102-103). Por esa razón, la entrega oportuna de Odebrecht pudo influir en la adjudicación de contrataciones públicas, porque tenían la trayectoria internacional, experiencia y capacidad para terminar las obras en el tiempo requerido, incluso antes, como símbolo de "eficacia” a partir de la cual los políticos puedan inaugurarlas.

En suma, un factor para la adjudicación fue la entrega oportuna, que se trataba de dar la "obra a tiempo" para satisfacer a sus clientes (presidentes, accionistas, etc), porque tenían la trayectoria empresarial, experiencia y eficacia para terminarlo en el plazo solicitado, incluso antes, a fin de que los políticos puedan inaugurarla para aumentar su capital político, o ganar votos. Por ello, Odebrecht y su entrega oportuna, fue atractivo para muchos gobiernos.

\subsection{INFLUENCIA EN EL ESTADO: “ARREGLOS BAJO LA MESA”}

Tan importante como la entrega oportuna, eran las relaciones externas de Odebrecht, porque tiene que ver con la capacidad de influencias excesivas que mantuvo en el Estado para asociarse a grandes obras públicas. Por esa razón, otro factor para ganar licitaciones fue la influencia en el Estado, porque crearon una red de corrupción con las esferas más altas de Gobiernos a partir del financiamiento electoral, sobornos, influyentes constructoras locales y lobbies para ganar licitaciones. En consecuencia, esto permitía mantener relaciones cercanas a largo plazo con una serie de importantes personajes como presidentes, ministros, directivos públicos entre otros para ganarse su "confianza”, evitar fiscalizaciones y adjudicarse contrataciones públicas mediante la corrupción.

En ese sentido, Odebrecht tenía un modelo de influencias donde usaban una serie de mecanismos, como sobornos, "lobbys”, "puertas giratorias”, financiamiento político, cuya finalidad era crear una red para ser "amigo de todos” y conseguir más obras con el mayor nivel de ganancias posibles (Durand 2018: 76). Por esa razón, en el 2006, la constructora brasileña creó una división llamada Departamento de Operaciones Estructuradas (DOE o mejor conocido como departamento de “sobornos") para gestionar varios mecanismos de corrupción blanda que varían entre lo legal, lo ilícito y lo antiético.

6 La Tecnología Empresarial Odebrecht (TEO) fue un principio de la firma brasileña para ser un grupo nacional y empezar su proyección internacional que satisfagan a sus clientes, Ver también, Norberto, Odebrecht, Tecnología Empresarial Odebrecht: sobrevivir, crecer y perpetuar, Salvador. Fundación Odebrecht, 2011, pp. 5-6. 
Asimismo, este departamento era importante por dos razones. En primer lugar, la autorización y presupuesto de las obras dependían de políticos y funcionarios públicos, y, por ende, debían ser incorporados a una red de corrupción que manejaba Marcelo Odebrecht para organizar los arreglos a través de una serie de mecanismos del DOE (Durand 2018:76-77). En otras palabras, era gente que debía ser ganada a su causa por su gran poder de influencia en las licitaciones públicas. En segundo lugar, los diversos mecanismos, como sobornos, financiamiento no declarado, “intermediarios” y empresas "offshore", fueron institucionalizados por Odebrecht como si fuesen actividades normales en su forma de operar para crear una red de corrupción a fin de lograr contratos y aumentar sus ganancias ${ }^{7}$. En suma, la importancia de su modus operandi radica en que incorporaron personajes influyentes a su red de corrupción y la formalizaron como una práctica cotidiana o normalizada de la empresa haciendo uso de diversos mecanismos que variaba entre lo legal, lo ilegal y lo dudoso.

En consecuencia, para mantener y ampliar las redes de corrupción, Durand sugiere que el modus operandi de Odebrecht fue en tres niveles: decisores, operadores y ejecutores ${ }^{8}$. En primer lugar, el nivel más alto era de decisores, porque se creó una relación especial entre el empresario y funcionarios públicos y políticos de primer nivel, incluso presidentes, para armar la red "desde arriba” y adjudicarse contrataciones públicas. Por ese motivo, el centro de la telaraña de corrupción de Odebrecht eran las relaciones privadas entre "los grandes jefes", Marcelo Odebrecht o, en su defecto, el responsable de cada país con las esferas más altas de Gobierno y partidos políticos, porque el modelo de influencias de Odebrecht aspiraba a tener contacto personal con los presidentes. En suma, el nivel de decisores era una relación entre jefes con un gran poder de influencia, pero indirecto en el proceso de licitación y, por ende, la necesidad de armar la red a niveles inferiores.

En segundo lugar, el nivel medio era de operadores, porque ellos participaban en el pago de sobornos del líder empresarial probablemente a los niveles alto y bajo. En efecto, en ese proceso de contacto participaban los intermediarios, o mejor conocidos como operadores, que servían para coordinar reuniones con los jefes de ambos lados (Durand 2018: 80-81). En breve, los operadores eran hombres de confianza de quienes estaban en un alto cargo público, de modo que si hay un destape de corrupción los “jefes” no se verían involucrados directamente.

En tercer lugar, el nivel bajo era de los ejecutores, porque ellos eran los encargados del comité de licitación y que en su mayoría eran administradores públicos con poder directo en el proceso de adjudicación, que fueron incorporados a la red a través de sobornos para garantizar que la constructora brasileña ganará obras, es decir, era gente encargada de decidir a quién se adjudica la contratación pública. En pocas palabras, para influir en el Estado, tener conexiones políticas y adjudicarse obras, Odebrecht organizó sus redes en tres niveles: decisores, intermediarios y ejecutores.

\footnotetext{
7 La Caja 2 fue una división creada por la constructora para el pago de sobornos y financiamiento no declarado a partidos políticos en países en los operaba. Ver también Gestión, ¿De qué se trata la Caja 2 de la empresa Odebrecht?, Lima, publicada el 15 de noviembre del 2018 https://gestion.pe/peru/politica/trata-caja-2-empresa-odebrecht-nndc-250048

8 De acuerdo con Durand, sus tres niveles de corrupción (decisores, operadores y ejecutores) eran clave para ganar licitaciones,Ver Francisco Durand, Odebrecht: la empresa que capturaba gobiernos, Perú, PUCP, 2018, pp. 80-82.
} 
En consecuencia, para conseguir más poder, su sistema funcionaba como un "arreglo bajo la mesa” entre la empresa que tenía el dinero, y los políticos, que autorizaban las obras desde arriba a cambio de "favores".

\subsubsection{FINANCIAMIENTO ELECTORAL: “DEUDA A FUTURO”}

Históricamente, en América Latina, el dinero y la política ha sido una relación problemática para las democracias, porque es dinero que busca beneficios particulares: contratos con el gobierno, acceso para influir en regulaciones favorables o, incluso, comprar impunidad cuando un gobierno entre en funciones. En la actualidad, se sigue el mismo destino, pero la preocupación tiene que ver con la forma en que se financia la política, es decir, cuando la entrega de dinero es a cambio de favores personales en contra del desarrollo social.

Por ello, el financiamiento político de Odebrecht era clave, porque no solo comprometía al político, sino que creaba un terreno fértil para luego armar la red desde arriba, es decir, “entre jefes”. En esa línea, el financiamiento electoral, que muchas veces no era declarado por los partidos, fue importante porque significa las bases para acceder a una relación cercana con el político con reuniones privadas; y mantener una relación especial a largo plazo con una serie de personajes influyentes como presidentes, ministros, congresistas, funcionarios, etc. Por eso, a medida que Odebrecht se iba internacionalizando, se dedicaron más recursos a la financiación de partidos para tener influencia ${ }^{9}$. En consecuencia, para que la empresa "sobreviviera", Emilio Odebrecht, padre de Marcelo, afirmó que en Brasil existía una regla de oro: "o se contribuía a todos, o a nadie” para ayudar a los partidos en sus necesidades de campaña y a cambio obtener favores (Durand 2018: 82).

\section{Gráfico 1: Financiamiento de Odebrecht a los partidos políticos en Brasil}

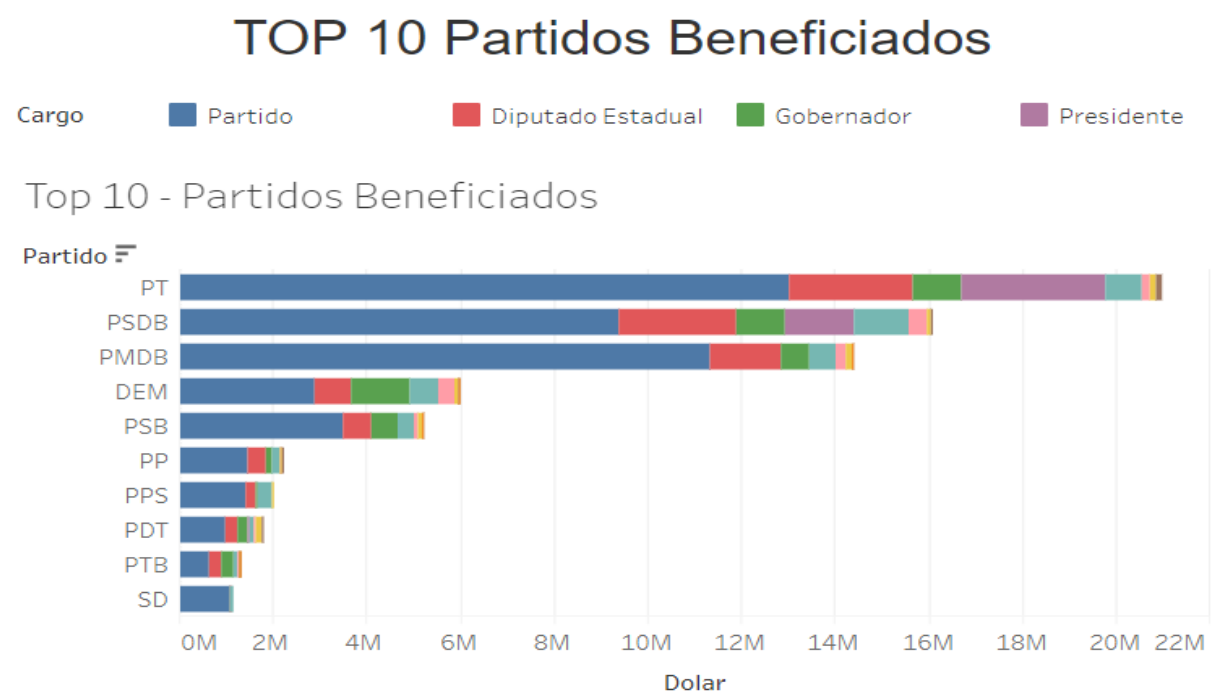

9 Solían financiar campañas políticas a todos los candidatos, incluso dar un paquete de servicios que ayudaban a los partidos políticos a competir ventajosamente. Ver también, IDL-Reporteros, Dinero para todos, Lima, publicado el 15 de marzo del 2018. https://idl-reporteros.pe/audios-jorge-barata-keiko-fujimori-ppk-alejandro-toledo-alan-garcia-susana-villaran/ 
Fuente: The Intercept Brasil y CONNECTAS

Por ejemplo, en Brasil, Odebrecht financió de forma oficial a 28 de los 35 partidos políticos. Pero solo tres de ellos concentraron más de la mitad de los aportes del grupo empresarial. Uno de ellos fue el Partido de los Trabajadores (PT) con tendencia izquierdista, que ha gobernado Brasil entre 2003 y 2016, quien lidera el top de las agrupaciones políticas que más dinero recibieron de Odebrecht con 21 millones de dólares, de los cuales puede ser dinero disfrazado para obtener ventajas en contrataciones públicas ${ }^{10}$.

Sin embargo, años después, los fiscales brasileños revelaron que el financiamiento de campaña era canalizado ilegalmente a través de la Caja 2, es decir sin reconocimiento del partido o candidato en sus cuentas oficiales, de modo que se puede tratar de un "pacto silencioso" entre el empresario y el candidato para aumentar las posibilidades de influir en un eventual gobierno sin generar sospechas.

En consecuencia, este financiamiento electoral de Odebrecht era como una especie de “acuerdo tácito" o "pacto silencioso" que creaba una deuda a futuro porque, por un lado, había una obsesión del empresario de recuperar el dinero invertido en campaña y, por otro, comprometía al candidato o político para devolverle el "favor" cuando llegue al poder. En otras palabras, era como un Quid pro quo, un intercambio de favores (algo por algo). Por ese motivo, Casas y Zovatto sostienen que es usual que empresas constructoras financien campañas puesto que sus negocios y ganancias dependen de contrataciones estatales y regulaciones públicas (2011: 22). No obstante, las contribuciones privadas en campañas electorales pueden ser peligrosas porque ponen en riesgo el interés público a tal punto de privatizar las decisiones de los funcionarios públicos por el apoyo brindado. En breve, el financiamiento electoral de Odebrecht creaba una deuda a futuro, porque comprometía a los políticos para luego devolverle el favor, significando el comienzo de la red de corrupción que iba en contra del desarrollo social. Es decir, si Odebrecht quería ser el “amigo de todos”, el financiamiento era el inicio de esa "amistad".

Asimismo, otra mecanismo importante del modus operandi de Odebrecht era formar alianzas estratégicas con influyentes constructoras locales para repartirse obras, incluso se convirtió en una necesidad para posicionarse en el mercado de cada país, porque a través de ellas no solo aprovechaban las debilidades institucionales del sistema, sino que aumentaban sus conexiones políticas para llevar a cabo sus obras en medio de sobornos, sobrecostos y baja fiscalización ${ }^{11}$.

En suma, la influencia en el Estado fue otro factor de Odebrecht para ganar licitaciones, porque crearon una red de corrupción a través del financiamiento electoral, sobornos, lobbies e influyentes constructoras locales con las esferas más altas de Gobierno que

10 El grupo Odebrecht solía financiar a todos los partidos políticos brasileños, donde los más consentidos eran los candidatos a presidentes, gobernadores, diputados del PT para luego tener acceso especial. Ver Belisario, Adriano, Los tentáculos de Odebrecht en las campañas políticas de Brasil, The Intercept y Connectas.

https://www.connectas.org/especiales/odebrecht/

11 Los clubes de la construcción solían repartirse contratos y ganancias para competir estratégica y ventajosamente sin competencia en los países que operaban. Ver también, La República, Club de la construcción ya existía desde el 2001, Lima, publicada el 6 de abril del 2019.

https://larepublica.pe/politica/1457054-club-construccion-existia-2001 
luego operaba a tres niveles (decisores, operadores y ejecutores). En especial, el financiamiento electoral era clave porque no solo significaba la base de esa red, sino que comprometía a los líderes políticos para mantener relaciones a largo plazo a fin de obtener ventajas en contrataciones públicas (deuda a futuro). Por ello, si Odebrecht quería ser "el amigo de todos”, el financiamiento electoral era el inicio de esa "amistad”.

\subsection{DEBILIDAD INSTITUCIONAL: “HECHA LA LEY, HECHA LA TRAMPA”}

Un tercer factor que influyó en la adjudicación fue la debilidad institucional, porque Odebrecht pudo aprovechar un contexto de "legislación débil” que no solo evitaba fiscalizaciones o rendiciones de cuentas, sino que facilitaba la corrupción para operar sin presiones, desafiando exitosamente el control de entidades públicas, partidos políticos, prensa, entre otros actores en la lucha contra la corrupción. En consecuencia, ganaban licitaciones de manera directa o, como se suele decir, adjudicaciones arregladas, porque no hay un sistema de peso y contrapesos que detenga esos comportamientos oportunistas.

Asimismo, el éxito de la entrega oportuna y la influencia en el Estado variaba según el país, porque su nivel de riesgo dependía de la institucionalidad de cada país para frenar la corrupción. Por ejemplo, en Estados Unidos, con entidades fuertes y rigurosa fiscalización, Odebrecht era como un "pez chico en una pecera grande”, porque no tenía el nivel de conexiones y contactos políticos como los tenía en Brasil y Perú, donde era un "pez grande en una pecera chica" (Durand 2018: 79). En otras palabras, el nivel de riesgo, o éxito, del "modus operandi” de Odebrecht dependía de la institucionalidad del país, porque hay países con "reglas más fuertes” y fiscalizaciones rigurosas, y otros simplemente son flexibles a la rapiña corruptela.

En consecuencia, la debilidad institucional fue aprovechada por Odebrecht para operar sin presiones. En esa línea, siguiendo la lógica de Quiroz, el éxito de su modus operandi se basa en defectos institucionales, porque se trata de una corrupción sistémica ("el que da”, "el que recibe” y “el que fiscaliza”) enraizada en las estructuras sociales y ligada a una evolución institucional precaria que no puede detener comportamientos oportunistas de empresarios, políticos y burócratas a fin de obtener ventajas personales contrarias al desarrollo social (2013: 33-34) ${ }^{12}$. En breve, el problema de la captura no se trata de cuestiones ideológicas, sino que la preocupación tiene que ver con "las reglas de juego" y sus “jugadores”, porque no hay un sistema de pesos y contrapesos para detener esos comportamientos oportunistas a través de recursos normativos y técnicos que fortalezcan a los actores encargados en la lucha contra la corrupción (los que fiscalizan). En efecto, esto trajo dos consecuencias: actores con baja capacidad sancionadora y la inmunidad.

En primer lugar, las entidades públicas, encargadas de luchar contra la corrupción no pueden proteger los intereses colectivos, porque no disponen de herramientas normativas y técnicas para prevenir, controlar y sancionar la corrupción. Asimismo, los funcionarios públicos que formaron parte de las redes de Odebrecht empleaban mecanismos de corrupción cada vez más sofisticadas que desafiaron las técnicas de

12 De acuerdo con el historiador Alfonso Quiroz, la corrupción es consecuencia de la debilidad institucional en un contexto donde las reglas de desarrollo y control o son inexistentes 0 , simplemente, son manipulables por estos "pactos silenciosos" entre políticos y empresarios. Ver Quiroz, Alfonso, La historia de la corrupción en el Perú, Lima, IEP, 2013. 
anticorrupción. Por ejemplo, los mecanismos habituales de Odebrecht como los sobornos, intermediarios, "doleiros" (personas que llevan dinero en maletas) entre otros tipos de acuerdos, son prácticas que pasan inadvertidas ante la "lupa" de los fiscalizadores (Portal 2018: 103) ${ }^{13}$. Como resultado, las entidades públicas no pueden cumplir los principios de eficacia y transparencia, que rigen a todo órgano público a partir del Derecho Administrativo, porque el lento proceso de control público no son equiparables para frenar los avances de la corrupción con mecanismos cada vez más sofisticados, de modo que benefician al interés personal en contra del público (Jinesta 2009). En pocas palabras, las entidades públicas no pueden prevenir, controlar y sancionar la corrupción de Odebrecht para ganar obras, porque sin una "ley clara" que los dote de capacidades técnicas son presa fácil” de la corruptela, con mecanismos que pasan inadvertidos y desafían con éxito los controles de fiscalización.

En segundo lugar, como las entidades no pueden sancionar la corrupción, un gran problema institucional fue la impunidad, la cual fue aprovechada por Odebrecht. De hecho, la impunidad fue su "materia prima", porque los funcionarios públicos que defendían puramente intereses personales, siguen operando sin ser castigados y, tienen incentivos para seguir delinquiendo en contra del desarrollo social. Dicho de otra manera, para ganar licitaciones, un elemento clave en las redes de Odebrecht era la impunidad, porque los funcionarios públicos, que deberían ser sancionados, siguen delinquiendo en contra del interés colectivo.

Sin embargo, como se sugiere líneas arriba, el modelo de influencia de Odebrecht empezaba a partir del financiamiento electoral para ganar licitaciones, porque era la base del "pacto silencioso". En ese sentido, en momentos electorales, las "reglas de juego" contra la corrupción no son capaces de frenar esos comportamientos oportunistas, porque los "vacíos legales" o "porosidades institucionales" son aprovechados por personajes oportunistas de los partidos políticos para "pitufear” o lavar el dinero, el cual no suele ser declarado ${ }^{14}$. En consecuencia, las entidades electorales no pueden fiscalizar este tipo de prácticas, porque sin un respaldo normativo, ni herramientas técnicas, ni "inteligencia financiera” pasan inadvertidas ante la lupa fiscalizadora; y, por ende, no logran el "enforcement" de la ley. En breve, son prácticas casi "invisibles" ante el fiscalizador, que sin apoyo normativo, técnico, etc, facilita la corrupción.

Asimismo, las leyes que regulan a los partidos políticos, que son actores claves en este "juego", no han significado cambios sustantivos para fortalecerlos, sino por el contrario los han expuesto fácilmente al poder económico y han hecho del dinero una forma perversa de relacionarse con grandes constructoras como Odebrecht. En esa línea, Tuesta señala que los partidos peruanos que son débiles y sin recursos propios están expuestos a quienes detentan los recursos económicos que se han extendido cada vez más hacia fuentes ilegales e ilícitas, y así acumular recursos, favorecerse o favorecer a terceros y eludir la justicia sin un control partidario interno y externo (2019). Es decir, sin una norma que los fortalezca, los partidos políticos para ganar sus campañas se han vuelto vulnerables al dinero de las corporaciones, quienes "influyen” para obtener “jugosos” beneficios a cambio de ganar obras para luego inflar sus costos y repartirse

13 Sin un esquema de prevención que sea dínámico y adaptables con normas a este fenómeno enraizado en las estructuras del Estado, los mecanismos de corrupción son casi invisibles ante la fiscalización. Ver Portal, Juan Manuel, "La fiscalización superior en el marco de combate a la corrupción", ¿Cómo combatir la corrupción?, México, 2018, pp.95-118.

14 El fondeo ilegal es una práctica habitual de los partidos políticos que es imposible de fiscalizar. Ver Amparo Casar, María let al.Dinero bajo la mesa. Financiamiento y gasto ilegal de campañas políticas en México, Ciudad de México, MCCl, pp. 9-12. 
ganancias ${ }^{15}$. En breve, los partidos políticos sin recursos propios y campañas cada vez más costosas están expuestos al dinero de corporaciones o al dinero mal habido a cambio de "favores".

En suma, la cuestión de la corrupción no solo se trata de Odebrecht y los líderes políticos, sino también de los que fiscalizan. Por ello, la debilidad institucional fue otro factor para ganar licitaciones, porque la firma brasileña aprovechó un contexto favorable de leyes "sastres" que no solo evitaban fiscalizaciones o rendiciones de cuentas, sino que facilitaba la corrupción, porque no hay un sistema de pesos y contrapesos que detenga esos comportamientos oportunistas. En especial, en momentos electorales, las entidades tampoco pueden prevenir, controlar y sancionar la corrupción, porque no cuentan con una "ley clara", que les disponga de dotaciones normativas y técnicas para defender los intereses colectivos. Asimismo, los partidos políticos, sin incentivos que los fortalezca, se han vuelto vulnerables al dinero de las corporaciones.

\section{ODEBRECHT Y SU MODUS OPERANDI EN PERÚ Y MÉXICO}

Perú y México son dos países involucrados en el caso Odebrecht en América Latina, los cuales comparten semejanzas y diferencias, porque aunque ambos son países que reportan altos niveles de corrupción, con políticos y obras públicas cuestionadas, igualmente poseen diferencias en ${ }^{16}$ sus sistemas de organización del Estado, siendo unitario y federal respectivamente. De esa manera su legislación y normativas para combatir la corrupción también difieren. En esa línea, el presente trabajo debe ser entendido en un contexto de "acuerdo establecido" entre Odebrecht y los líderes políticos de cada país para influir ventajosamente en sus Estados a través del financiamiento electoral, lobbies, sobornos, influyentes constructoras locales en relación a los tres factores presentados ( sistema que facilita la corrupción), donde el financiamiento electoral es clave porque no solo se trata del inicio de la red, sino que significa la base de ese "pacto silencioso".

15 Los partidos sin apoyo de dinero estatal se han vuelto vulnerables al dinero de las corporaciones y grupos de interés. Ver también, Tuesta Soldevilla, Fernando, Con mi dinero no te metas, Perú, Comercio, publicado el 27 de marzo del 2019. https://elcomercio.pe/opinion/columnistas/lava-jato-financiamiento-partidos-reforma-mi-dinero-metas-fernando-tuesta-soldevillanoticia-638886

16 Perú y México comparten una corrupción a causa de una constante cultural con percepciones altas de este fenómeno después de casos como Lava Jato. ¿Pero esto realmente se debe a la cultura 0 un precario desarrollo institucional con normas que incentivan la conducta de los individuos para corromperse?. Ver gráfico 2. 


\section{Gráfico 2: Percepciones de políticos involucrados por corrupción en Perú y México}

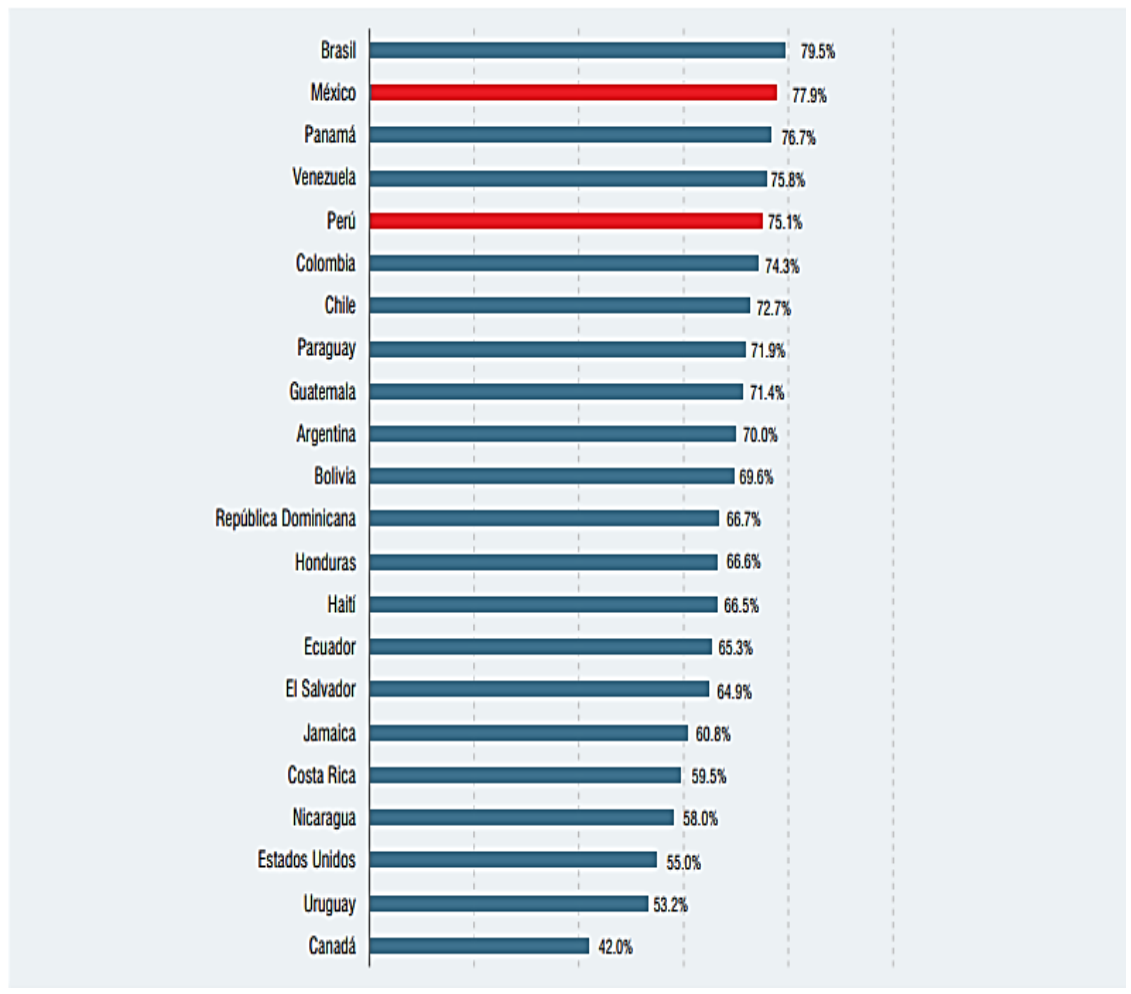

Fuente: Barómetro de las Americas 2016-2017. En Hacia la Democracia del Bicentenario. (CANRP) 1era edición mayo del 2019.

Para fines del presente trabajo, la corrupción es entendida como el mal uso del poder empresarial, político y burocrático para obtener ventajas personales en contra del desarrollo social (Quiroz 2013: 30) usando los siguientes mecanismos que varían entre lo legal, ilegal y antiético ${ }^{17}$ :

1. Soborno es un arreglo ilegal entre una autoridad-funcionario público y el empresario mediante la entrega de dinero para ganar licitaciones.

2. Leyes "sastres" son normas para incentivar la conducta en cierto fin que evitan las fiscalizaciones y rendiciones de cuentas, facilitando la corrupción.

Por ello, una vez resumidos los mecanismos de captura, el estudio se centrará en tres factores del sistema de "conquista” de Odebrecht a partir de dos megaproyectos en Perú y México: Metro de Lima Línea 1 y Refinería Miguel Hidalgo Tula I.

\footnotetext{
${ }^{17}$ Estos mecanismos están vinculados a la "corrupción blanda” entendida como conductas oportunistas para obtener ventajas personales mediante prácticas "legales". Ver Arturo Del Castillo: "Medición de la corrupción: un indicador para la rendición de cuentas”.
} 


\subsection{METRO DE LIMA LINEA 1- PERÚ}

El Metro de Lima, antes llamado Tren Eléctrico, es un proyecto antiguo de transporte que empezó con Alan García, pero que no fue terminado por denuncias de corrupción durante su primer Gobierno (1895-1990). De hecho, el Metro de Lima es un caso emblemático del sistema de Odebrecht para ganar obras, pues fue un contexto de acuerdos establecidos entre el Gobierno y la empresa, lo cual solo refuerza la tendencia nacional de corrupción persistente en la historia peruana por las siguientes dos razones.

Por un lado, el Tren Eléctrico se inició durante su primer Gobierno y estuvo a cargo del Consorcio Tralima, dirigida por una empresa italiana de Sergio Siragusa Mule, quien tiempo después revelaría que pagó sobornos para facilitar el proyecto de construcción. Asimismo, en 1993, ante los fiscales, atestiguó que él mismo había entregado dinero en efectivo y realizado depósitos a una cuenta del Barclays Bank de Gran Caimán perteneciente a Alfredo Zanatti, amigo íntimo de García, por unos siete millones de dólares para ganar la adjudicación (Quiroz 2013: 343). En consecuencia, el Tren Eléctrico, ideado en 1896, sería uno de los muchos casos de corrupción investigado tras su salida y un proyecto abandonado de gobierno en gobierno (Fujimori en 1990-2000 y Toledo 2001-2006) como símbolo de ineficiencia, incluso “vergüenza”, de su primer gobierno.

Por otro lado, dieciséis años después, la historia parece repetirse. El proyecto fue retomado en el 2006, cuando Alan García fue elegido presidente por segunda vez. Asimismo, luego de que en el 2001 prescribieron cualquier cargo en su contra, el presidente priorizó personalmente que el Metro de Lima saliera adelante con la finalidad de culminar esa obra inconclusa, la cual había sido símbolo de fracaso de su primer gobierno, por lo que se motivó a construirlo a cualquier costo, incluso haciendo uso de arreglos “bajo la mesa” (Durand 2018: 135). En breve, el Metro de Lima se convirtió para García en una deuda personal que debía cumplir a toda costa, incluso incurriendo en prácticas corruptas.

Por ello, el 2 de marzo del 2010 el consorcio Tren Eléctrico de Lima, conformado por Odebrecht y Graña y Montero, ganaría la licitación para llevar a cabo la obra, en medio de denuncias de corrupción por sobornos, sobrecostos y tráfico de influencias a cambio de obtener ventajas en la licitación de la Línea 1 del Metro de Lima durante su segundo gobierno (Informe Lava Jato 2019, IDL-Reporteros 2018 y La República 2019). Así, el Metro de Lima se convertiría en uno de los tantos casos de corrupción que serían investigados.

Sin embargo, el gran problema no solo es acerca de corrupción, sino que existe un sistema que la facilita en el país. En esa línea, Quiroz afirmaba que la historia de la corrupción en el Perú es cíclica, porque se trata de un sistema de corrupción ya existente, enraizado en las estructuras centrales de la sociedad, en la formación del Estado y ligada a una evolución institucional precaria que no ha podido detener comportamientos oportunistas en contra del desarrollo social ${ }^{18}$.

18 De acuerdo a su tesis, la corrupción sistemática entre el que da, el que recibe y el que observa, se da cuando las reglas formales al desarrollo, formales e informales, son inexistente, inestables o distorsionadas para los free behavior.Ver Quiroz, Alfonso. La historia de la corrupción en el Perú. Lima, IEP, 2013, p. 33 
En ese sentido, resumido el contexto, se explica por qué Odebrecht pudo influir en el Estado peruano para adjudicarse el Metro de Lima. Por ello, se sostiene que hubo un acuerdo entre la firma brasileña y las esferas más altas del gobierno aprista a partir de tres razones: entrega oportuna, influencia en el Estado y debilidad institucional. Dicho de otro modo, en contra de la sabiduría popular que ve a Odebrecht como emblema de corrupción en la actualidad, se presenta un caso que va más allá de la corrupción en sí misma, sino que identifica sus factores para ganar licitaciones en un país donde la corrupción tiene largos antecedentes.

En primer lugar, un factor clave para ganar la licitación del Metro de Lima fue su entrega oportuna, pues la constructora tenía la eficacia para terminarla antes de que García acabe su mandato. Dicho de otra manera, esta cualidad cumplía sus expectativas políticas a fin de inaugurarla antes de que culmine su periodo de gobierno (2006-2011), porque se trataba de una necesidad política por una obra inconclusa durante su primera gestión (1985-1990).

En esa línea, culminar esa obra era una prioridad política para el expresidente aprista. De hecho, el exdirectivo de Odebrecht en el Perú revelaría lo siguiente: "Era el proyecto más importante que el presidente tenía en su gestión, ¿no? Porque era una obra en la ciudad, visible, de la que mucha gente iba a tomar conocimiento, como lo tomó. Cada cruce, cada interrupción que hacía en las calles era publicado en los periódicos [...] [Alan García] sabía que era una obra que tenía un impacto político importante para él y tenía que resolver ese problema el proyecto" (IDL-Reporteros 15 de octubre del 2017). En breve, era una necesidad política de García que Odebrecht podría ayudar a cumplirla por la fama de la firma brasileña para construir obras en tiempo record.

Sin embargo, un problema que enfrentaba García era que varias empresas no se animaban a presentarse en los concursos de licitación de la obra, ya que la forma de financiamiento era un contrato totalmente desequilibrad. Incluso la convocatoria fue declarada desierta en muchas ocasiones y el presidente no podía ampliar plazos, pues quedaba poco tiempo antes de que termine su gobierno. Por ello, Alan García estaba cansado de la ineficiencia de Proinversión, encargada de la concesión del Metro de Lima, motivo por el cual pasó el proyecto de la Municipalidad de Lima al Ministerio de Transporte y Comunicaciones para dar viabilidad y rapidez a la ejecución del proyecto (IDL-reporteros 2019). En ese momento, los años pasaban y la obra emblema del gobierno de García seguía inconclusa ${ }^{19}$.

Por esa razón, la obra debería estar lista antes de que acabe su mandato, y Odebrecht probablemente era la única empresa para cumplirlo en ese tiempo, puesto que tenía la experiencia empresarial para culminar en tiempo record, y si es necesario trabajar triple turno para terminarla ${ }^{20}$. Por su parte, había un constructora china que buscaba ejecutar la obra, no obstante no llegaba a presentarse en el concurso, pues no tenía una propuesta viable; en cambio, Odebrecht contaba con una trayectoria empresarial, una propuesta técnica viable, y era la única empresa con una alta calificación para ganar la licitación,

19 Entre pasar del MML al MTC la facultad del Metro, a García le quedaban menos de dos años para terminar el Metro, Ver también, IDL-Reporteros, Así habló Barata: las confesiones del ex jefe de Odebrecht desde Curitiba, Perú, publicado el sábado 04 de mayo del 2019. https://idl-reporteros.pe/asi-hablo-barata/

20 https://idl-reporteros.pe/asi-hablo-barata/ Odebrecht trabajo a triple turno para terminarla a dos semanas de que García dejó la banda presidencial. Ver, El País, Alan García dice adiós con la inauguración del Metro de Lima, Perú, publicado el 11 de julio del 2011. https://elpais.com/internacional/2011/07/11/actualidad/1310335216_850215.html 
porque había construido decenas de obras en todo el mundo, incluso en Europa , EEUU y demás países en tiempo record (IDL- Reporteros/ declaraciones de Jorge Barata ante fiscales brasileños en el 2016).

En esa línea, Odebrecht ganaría la adjudicación el 2 de marzo del 2010 en consorcio con Graña y Montero, terminando el primer tramo el 11 de julio del siguiente año para que García lo inaugure (IDL-Reporteros 2018). Es decir, la firma brasileña entregó la obra en quince meses para que García estrene el primer tramo del Metro de Lima ante una alta presencia pública y medios de comunicación, olvidando la obra que se dejó inconclusa durante su primer Gobierno.

En suma, sobre la entrega oportuna, la inauguración del Metro de Lima fue el 11 de julio del 2011, es decir, a dos semanas que culmine su gobierno (El País 2011). Por ello, Odebrecht influyó para ganar la licitación del metro, porque tenía la trayectoria empresarial, experiencia y eficacia para terminarla en un tiempo conveniente para el gobierno de García, el cual arrastrada esa obra como promesa desde 1986; y, a su vez, García recibía el mérito o redito político por haberla construido.

En segundo lugar, otro factor en la adjudicación, fue la influencia de Odebrecht en el Estado, porque crearon una red de corrupción con las esferas más altas de Gobierno aprista en tres niveles empezaba con el financiamiento electoral hasta la conformación de una alianza colusiva con Graña y Montero, influyente constructora local. Dicho de otro modo, armaron una compleja red de corrupción con la élite política que le permitió mantener una relación especial a largo plazo con el presidente, ministros y altos directivos públicos entre otros personajes importantes a través del financiamiento de campañas, sobornos, empresas locales, lobbies, entre otros mecanismos. Esto era el lado "oscuro" de Odebrecht que ha sido poco estudiado por la literatura, y que siempre iba acompañado de su entrega oportuna ("lado bueno de la empresa”).

Para empezar, el financiamiento electoral era clave porque significaba la base para acceder a una relación especial con el político a largo plazo. Por esa razón, Odebrecht solía financiar campañas políticas, entre ellas, según declaraciones de Jorge Barata, entregaron un aporte de US\$200 mil al exministro aprista Luis Alva Castro, quien se presentó como intermediario de Alan García para la campaña presidencial del 2006 a través de la Caja 2 (Convoca y Ojo Público el 23 de abril del 2019) ${ }^{2122}$. De hecho, Jorge Barata reconoce que aportar a su campaña le ayudó a "abrir las puertas” para coordinar reuniones íntimas entre Marcelo Odebrecht y el presidente en Palacio de Gobierno, y "negociar" los diferentes proyectos que llevarían a cabo; declarando lo siguiente: "Si nosotros no hubiéramos hecho un aporte de campaña, difícilmente íbamos a tener una reunión tan pronta, tan rápida y con tanta disponibilidad del gobierno", porque las empresas que no ayudan, no son ayudadas" (IDL-Reportero 5 de mayo del 2019). En breve, el financiamiento electoral de Odebrecht creaba un terreno fértil para mantener una relación especial con personajes políticos muy influyentes sobre la base de la corrupción.

21 De acuerdo a Barata, hicieron aportes no contabilizados a pedido de Alva Castro, quien se presentó como el intermediario de García. Ver también, Ojo Público, Odebrecht pagó US\$200 mil para campaña aprista a través de intermediario de Alan García, Perú, publicado el 23 de abril del 2019 https://ojo-publico.com/1164/odebrecht-pago-us200-mil-para-campana-aprista-traves-deintermediario-de-alan-garcia

22 https://ojo-publico.com/1164/odebrecht-pago-us200-mil-para-campana-aprista-traves-de-intermediari o-de-alan-garcia 
Asimismo, el financiamiento electoral creaba una deuda a futuro, pues comprometía al político para devolverle el "favor". Por ello, como sostiene Marcelo Odebrecht, su intención era apoyar a todos los candidatos presidenciales de Perú, todos los partidos y congresistas, incluso sabiendo que no iban a salir elegidos, los apoyaban, porque la oposición también podría causar problemas; y, entonces, era lógico financiarlos para incluirlos en su red (IDL-Reporteros 2017) ${ }^{23}$.

Sin embargo ese financiamiento solía ser ilegal, debido a que eran aportes no declarados, para que no despierten sospechas si Odebrecht recibía una licitación. Por ese motivo, la constructora hizo aportes a la campaña de García que provenían de la Caja 2 del Departamento de Operaciones Estructuradas, es decir, dinero "no contabilizado"; o como señala Marcelo, "se usaba mucho la Caja 2, porque se estaba escondiendo que estábamos apoyando a determinados políticos (IDL-Reporteros 2017 confesiones de Marcelo).

Según investigaciones de IDL-Reporteros, de los 200 mil dólares confesados por Barata, se ha demostrado la entrega de 100 mil dólares. Estos aportes fueron repartidos de dos maneras: por un lado, \$60 mil dólares a 'Laque', que es el seudónimo, de Luis Alva Castro; y, por otro lado, \$40 mil dólares, al ‘Apra’, que no figura con seudónimo alguno, y que corresponde al Partido Aprista Peruano como lo revela el siguiente documento del DEO:

\section{Imagen 1: el “APRA”, “Laque” y la Caja 2}

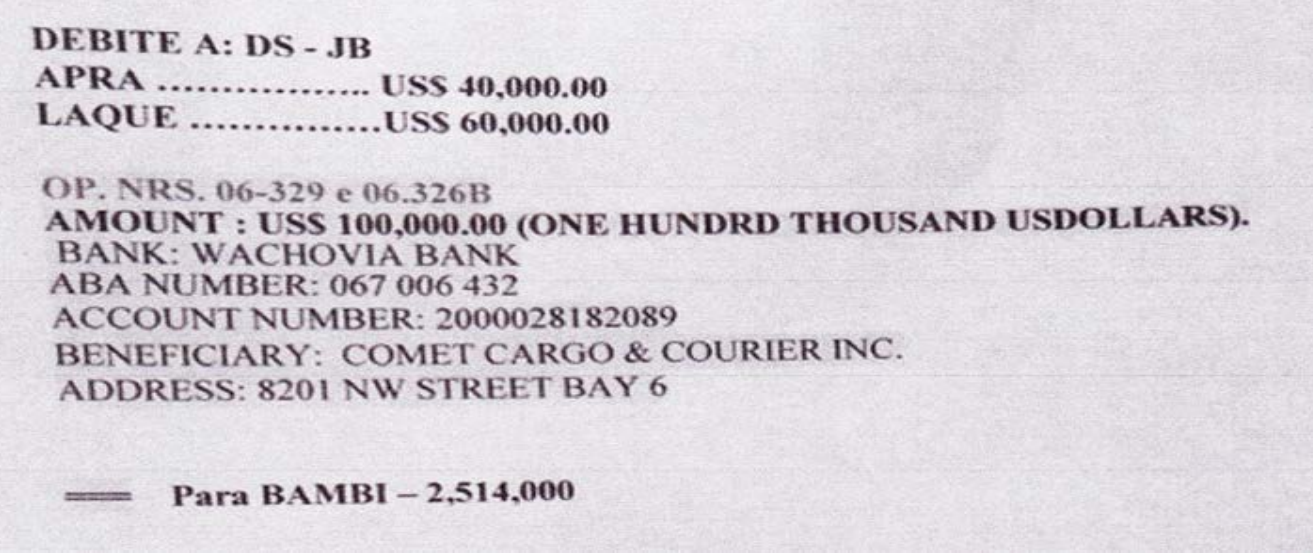

Fuente: IDL-Reporteros, publicado el sábado 06 de abril, 2019 a las 19:40.

En esa línea, registros en los servidores del DEO e informes judiciales, les permiten afirmar que el seudónimo 'Laque' corresponde a Luis Alva Castro; y que el de 'Apra' designa al Partido Aprista Peruano (IDL-Reporteros 2019). Por su parte, curiosamente, Luis Alva Castro aparece como uno de los mayores aportantes apristas en la campaña

23 De acuerdo a Marcelo Odebrecht, apoyaron a todos los candidatos a presidentes, congresistas, etc. Ver IDLReporteros, Apoyamos a todos, Perú, publicado el 30 de diciembre del 2017.

https://idl-reporteros.pe/apoyamos-a-todos/ 
electoral del 2006, de acuerdo con las investigaciones realizadas sobre la base del reporte oficial de sus campañas política, tal y como lo revela el siguiente gráfico:

\section{Gráfico 3: el mayor aportante aprista en la campaña del 2006: Luis Alva Castro}

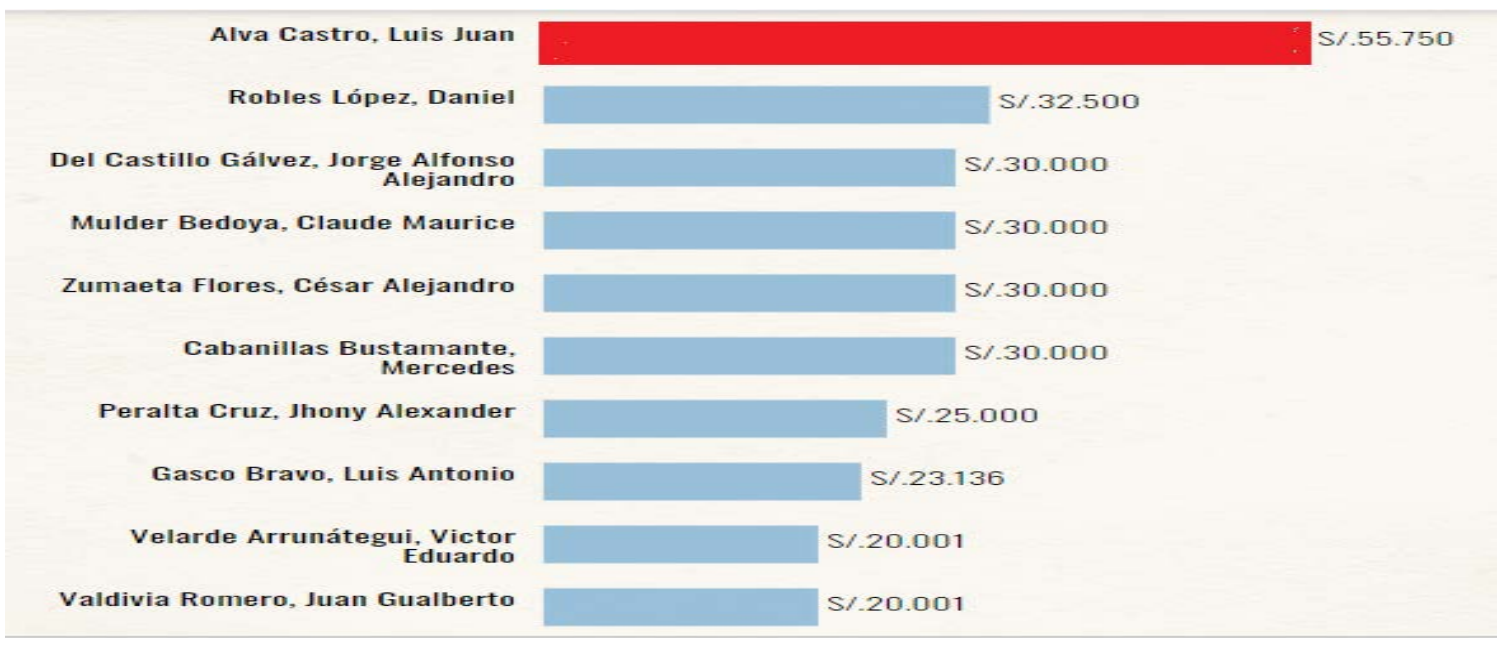

Fuente: Ojo Público en Fondos de Papel PAP-ONPE

En consecuencia, el financiamiento electoral fue la base para continuar con la red de corrupción durante el Gobierno a fin de ganar obras. Es decir, con los aportes no declarados, el financiamiento político de Odebrecht era un "pacto silencioso" que no solo endeudaba al político, sino que la red continuaba forjándose, casi de inmediato en el gobierno, para continuar expandiéndose a niveles inferiores (Durand 2018: 140).

De esa manera, para ganar la licitación del Metro de Lima, durante el Gobierno de García la red de corrupción fue de tres niveles. En primer lugar, el nivel de “jefes” era entre García y Marcelo, este empezaba desde el financiamiento electoral. En segundo lugar, el nivel de "intermediarios" era entre Luis Nava, secretario general del Palacio de Gobierno y amigo íntimo del García, Jorge Cuba, viceministro de comunicaciones y personaje cercano a Cornejo (ministro del Ministerio de Transporte y Comunicaciones); y Jorge Barata, quien era el nexo entre Odebrecht y el gobierno. Finalmente, el tercer nivel de "ejecutores", donde Barata se relacionaba con los encargados de aprobar la licitación del Metro de Lima, como Mariella Huerta, Edwin Luyo y Santiago Chau (Durand 2018:140-142). De ese modo, se creó una red de corrupción, que empezaba desde el financiamiento electoral, entre Odebrecht, el Gobierno y otros personajes para luego ser estructurado en tres niveles (jefes, intermediarios y ejecutores), como lo revela el siguiente gráfico:

\section{Gráfico 4: Metro de Lima y su red en tres niveles}




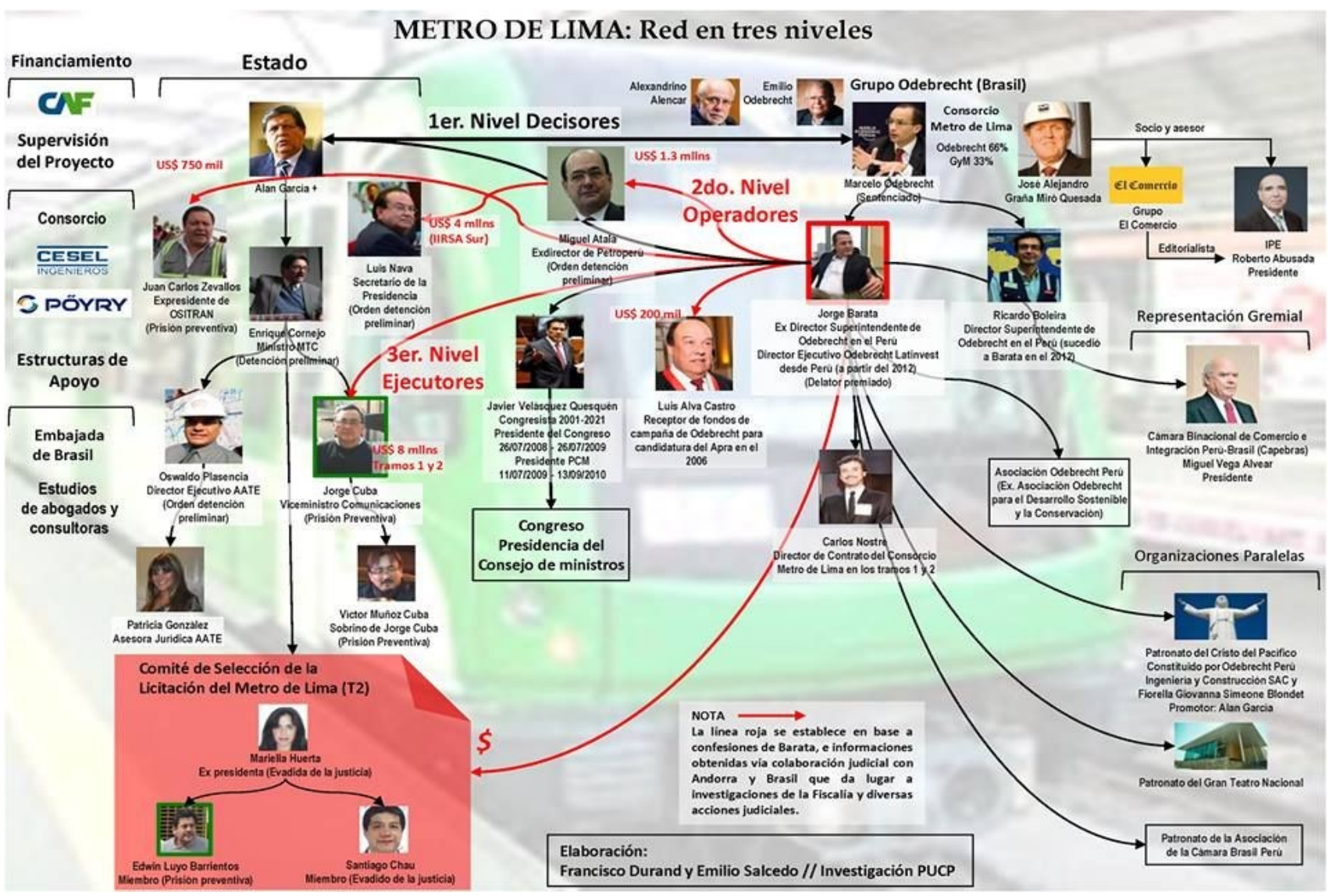

Fuente: Francisco Durand y Emilio Salcedo en investigaciones PUCP

Estas relaciones se lograban través de "arreglos" colusivos con Cuba y otros funcionarios del MTC, los cuales participaban en la toma de decisiones del Comité de Licitación del Metro de Lima Tramo 1, para posteriormente recibir sobornos en cuentas y empresas offshore de Andorra provenientes del DEO. Por ello, fueron 8 millones 100 mil dólares en coimas por el Metro de Lima, hasta ahora confesadas por Jorge Barata que se pagaron a través del Departamento de Operaciones Estructuradas (DEO) para ganar la licitación (Informe Lava Jato, IDL-Reporteros 2018). Asimismo, otro gran problema de la corrupción fue el sobrecosto. Este se incrementó en $26.5 \%$ para el tramo I en comparación con su valor base, mientras que en el tramo II, fue de 54.4 \%. Es decir, terminaron costando casi 2 mil millones de dólares por sobre su valor real, además de las coimas confesadas a Edwin Luyo y Santiago Chau, personas con gestión directa en el proceso de licitación, como lo revelan las investigaciones en el siguiente gráfico:

\section{Gráfico 5: Sobrecostos y sobornos del Metro de Lima}




\section{¿CUÁNTO COSTÓ EN REALIDAD EL TREN ELÉCTRICO?}

El Estado ha pagado dos veces por el mismo proyecto durante los dos gobiernos de Alan García. Los tramos 1 y 2 de la Línea 1, iniciados en el primer gobierno y culminados en el segundo, terminaron costando en total cerca de 2 mil millones de dólares (actualizando los valores del primer gobierno de García). Y se desembolsaron, según lo confesado, coimas por 10 millones de dólares.
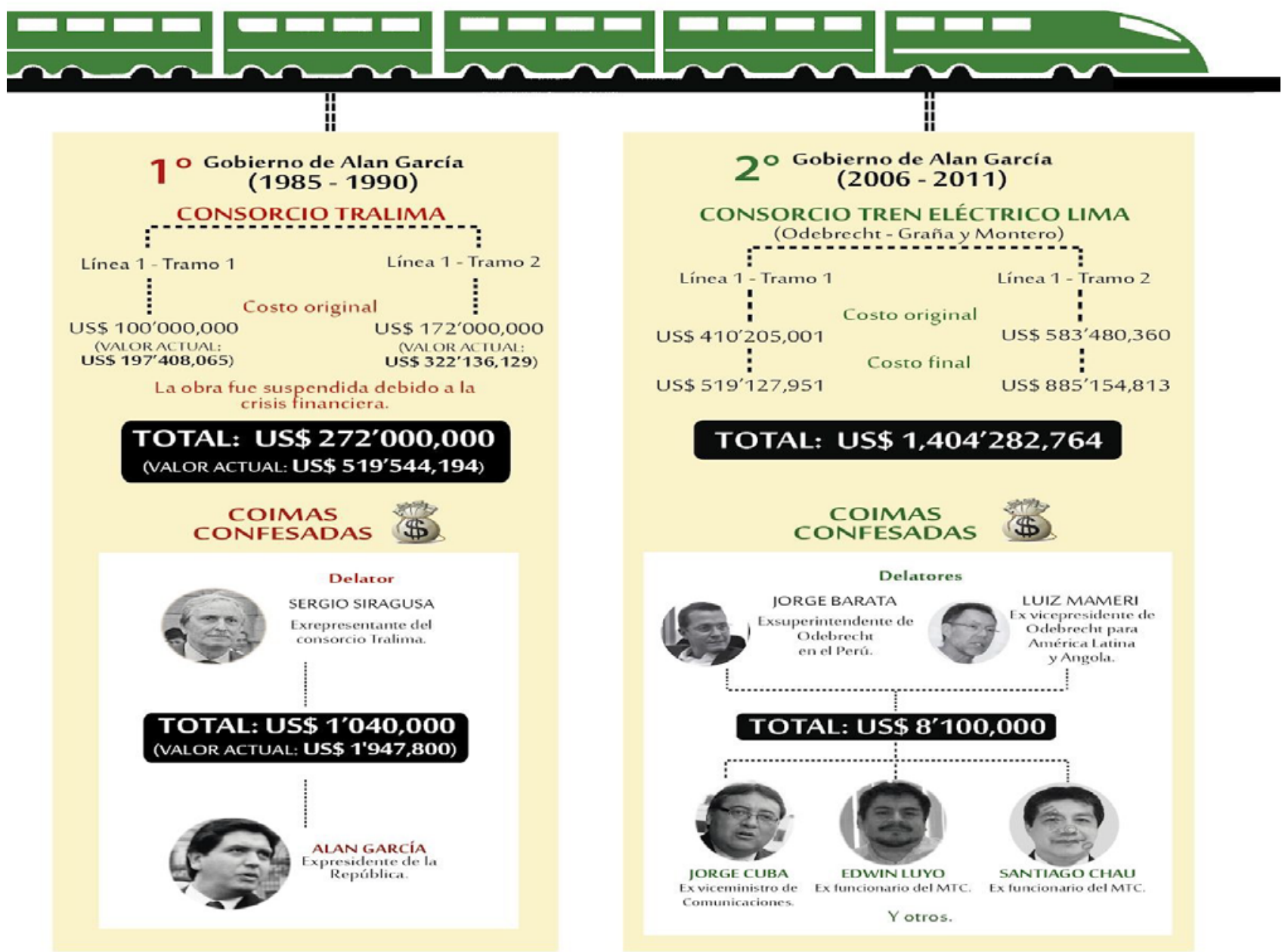

TOTAL: US\$ $1,404^{\prime} 282,764$

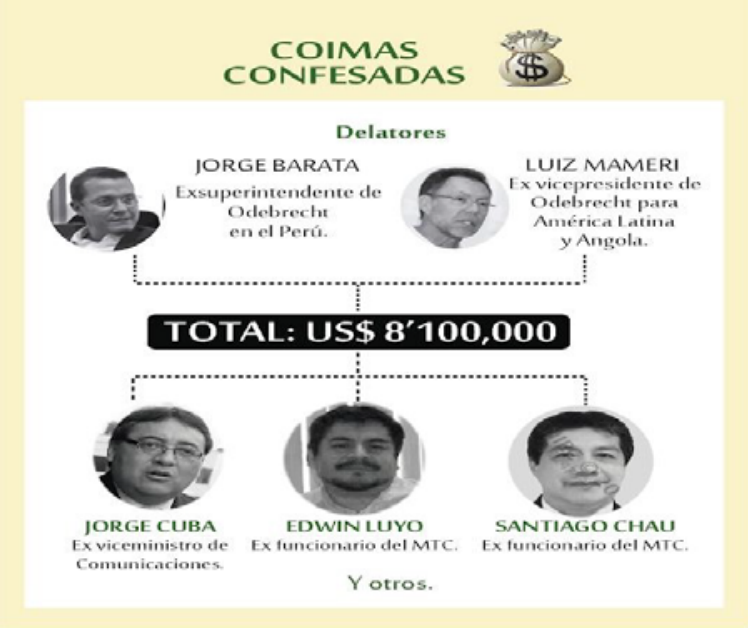

Elaboración: IDL-Reporteros

Fuente: IDL-Reporteros publicado el jueves 21 de septiembre, 2017 a las 17:22.

Asimismo, en el nivel 2, el de los intermediarios, Luis Nava Guibert fue un personaje clave en la red del Metro de Lima, exsecretario de la presidencia de la República y amigo de confianza de García. Es decir, era el nexo que facilitaba la relaciones entre el presidente García con Odebrecht, pues tal como reconoce Barata ante los fiscales peruanos, para él "hablar con Nava era como hablar con el mismísimo expresidente" (IDL-Reporteros 2019 en Así Habló Barata).

En esa línea, fue él quien sugirió a Miguel Atala, el cual posiblemente actuó como testaferro del expresidente a través de una cuenta "offshore" en la Banca Privada de Andorra, donde recibió sobornos de 1 millón 300 mil dólares del $\mathrm{DEO}^{24}$. Años después

24 De acuerdo a Miguel Atala, vicepresidente de Petroperú, el dinero depositado en su cuento era en realidad para Alan García. Ver, Gorriti, Gustavo, Las confesiones de Miguel Atala,publicado en IDL-Reportero publicado el martes 30 de abril, 2019 a las 8:53

https://idl-reporteros.pe/la-confesion-de-miguel-atala/ 
en declaraciones ante la Fiscalía, reconoció lo siguiente: “que recién en el año 2008, tomó conocimiento que el dinero que estaba depositado en la cuenta Ammarin Investment INC, que era de mi titularidad, por el monto de US\$1,312,000, era en realidad del presidente Alan García Pérez” (IDL-Reporteros 2019 en confesión de Miguel Atala). Es decir, los sobornos de Odebrecht a las cuentas offshore de Atala, recomendado por Luis Nava, tenían como beneficiario del dinero al expresidente, tal como lo revela la siguiente transcripción.

\section{Imagen 2: Las confesiones de Atala sobre Alan García}

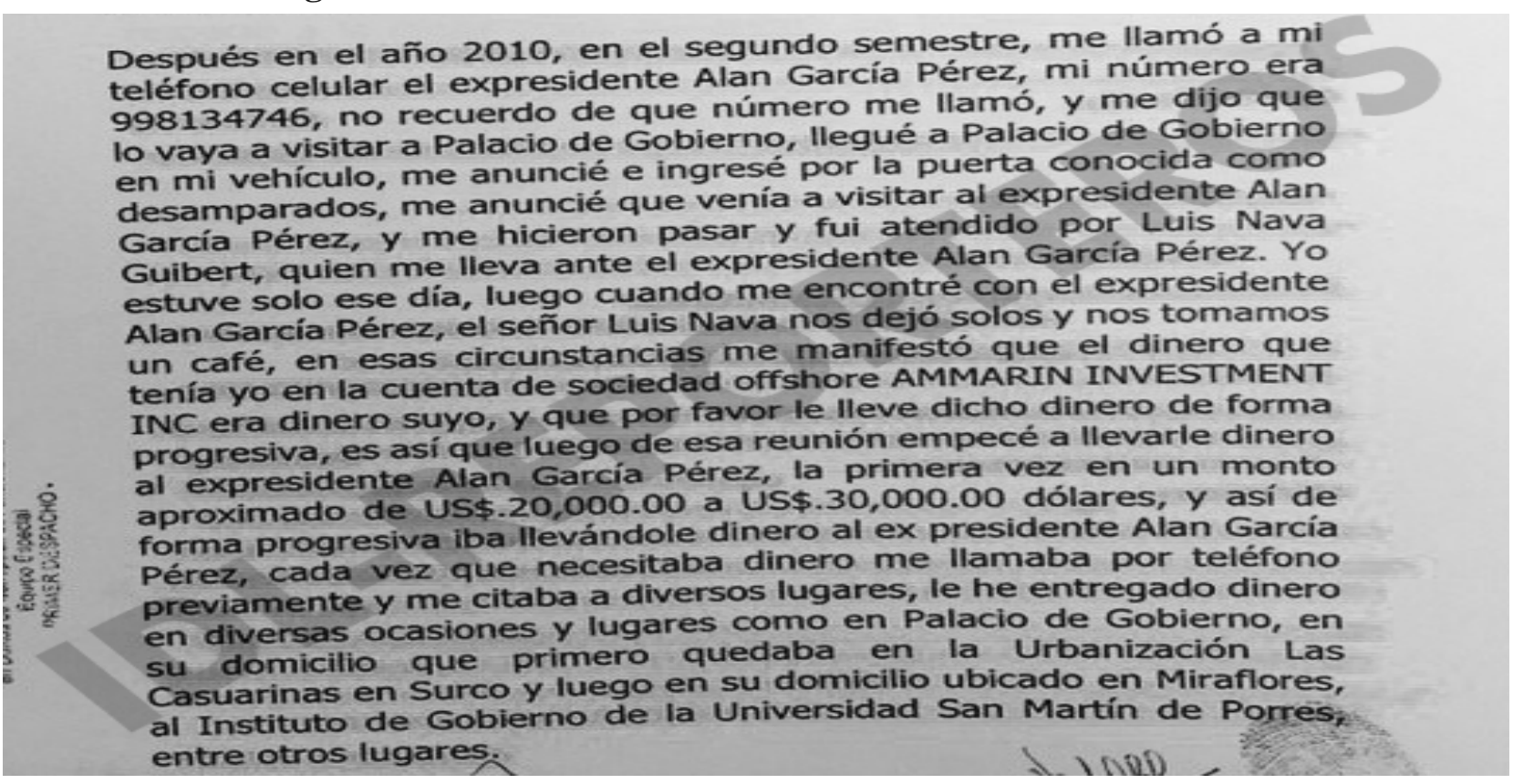

Fuente: Informe Lava Jato en IDL-Reportero publicado el martes 30 de abril, 2019 a las 8:53

Por otra parte, para Odebrecht, era una necesidad formar alianzas con constructoras locales, puesto que son muy influyente en el país y pueden conocer y aprovechar las debilidades de sistema ${ }^{25}$. En esa línea, El grupo Graña y Montero, la constructora más importante del Perú, acompañó a la firma brasileña en el Metro de Lima y ganaron esta licitación con el Consorcio Tren Eléctrico Lima, quienes realizaron otras grandes obras durante el Gobierno aprista: IIRSA Norte y Sur, y el Gasoducto del Sur (Durand 2018: 162-163). Es decir, era una constructora local que mantuvo relaciones "estrechas" con el gobierno de García y sus relaciones con los diferentes niveles del Estado fueron frecuentes y favorables para sus negocios.

En suma, sobre la capacidad de influencia, Odebrecht pudo adjudicarse el 2 de marzo y 10 de junio del 2010 el tramo 1 y 2 del Metro de Lima respectivamente, puesto que crearon una red de corrupción con las esferas más altas del Gobierno aprista en tres niveles (decisores, intermediarios y ejecutores), usando financiamiento de campañas, sobornos cuentas offshore, entre otros mecanismos para ganar la licitación; así como mantener relaciones estratégicas con Graña y Montero, la constructora más importante

25 Graña y Montero, miembro del club de la construcción, confesó haber realizado sobornos para la adjudicación de una obra. Ver también, La República, Graña y Montero admitió que pagó soborno de S/ 12.5 mllns, Perú, publicado el 07 de junio del 2019. https://larepublica.pe/politica/1483640-grana-montero-admitio-pago-soborno-s-125-mllns 
del país. Asimismo, esa red empezaba desde el financiamiento electoral y era clave, ya que comprometía a García para retribuir el apoyo” brindado a través del financiamiento, el cual se construyó como una deuda a futuro. De esa manera se crearon las bases para mantener, con la futura coalición gobernante, una relación especial a largo plazo; con personajes muy influyentes que se encargaran del proceso de licitación directa o indirectamente. Entonces, si Odebrecht quería ser el "amigo de todos”, el financiamiento era el principio de esa "amistad"

En tercer lugar, un último factor en la licitación fue la debilidad institucional que hay en el país, pues Odebrecht aprovechó un contexto de legislación débil que facilitó la corrupción, usando sus diferentes mecanismos ("lobbys", sobornos, financiamiento de campañas, etc), los cuales variaron entre lo legal, lo ilegal y lo dudoso, pasando siendo imperceptibles al control de entidades públicas, partidos políticos, prensa, entre otros actores en la lucha contra la corrupción. Dicho de otro modo, no hay un sistema de pesos y contrapesos que pueda detener los comportamientos oportunistas, porque no cuentan con una "ley clara", que les disponga de recursos normativos y técnicos para prevenir, controlar y sancionarla, sino por el contrario la facilita.

Por esa razón, para cada obra, se les creaba un marco legal beneficioso a través de leyes, decretos y resoluciones hechas especialmente para Odebrecht. En esa línea, en el 2006, se aprobó la Ley 28670, o también conocida como la “Ley Odebrecht”. Aquella facilitaba la corrupción, porque ignoraba un sistema de rendición de cuentas, declarando al Metro de Lima como prioridad y necesidad pública, incluso otros proyectos como la Interoceánica Sur y el Gasoducto (2006, art.1) ${ }^{26}$. Es decir, era una ley ad hoc que no solo burlaba filtros básicos de transparencia y regulación, sino que podría ser evidencia sobre un caso de "captura normativa" como recurso clave para ganar licitaciones, porque creaba un contexto legal favorable, incluso general, para que el sistema de Odebrecht pueda tener éxito; siempre acompañado con su entrega oportuna y los “arreglos bajo la mesa”.

Por ejemplo, entre el 2010-2011, se aprobó el decreto supremo 081-2010-EF: un marco normativo-administrativo importante que generaba un contexto colusivo para beneficiar a la constructora brasileña. Esta norma, creada en favor de Odebrecht, era clave para el Metro de Lima, porque evitaba fiscalizaciones incómodas por parte de la Contraloría General de la República (autoridad que vigila el correcto uso de los recursos estatales); y dicho decreto en cuestión fue aprobado, curiosamente, por García y los ministros Cornejo (Comunicaciones y Transporte encargado de la obra) y Mercedes Araoz (Economía y Finanzas) (Durand 2018:158). En breve, el contexto legal pudo facilitar el proceso para que Odebrecht gane la licitación, porque evitaba incómodas fiscalizaciones de las entidades encargadas de luchar contra corrupción y, por el contrario, aceleraba el proceso de adjudicación, fomentando la corrupción.

\footnotetext{
${ }^{26}$ La Ley pro Odebrecht fue coordinada por el congresista Gilberto Díaz y Toledo, donde se declara como interés nacional al Metro de Lima, IIRSA Sur, Trasvase Olmos, etc. Ver, Ley $N^{\circ} 28670$ : ley que declara como necesidad pública e interés nacional diversos proyectos de inversión, Congreso de la República Perú, promulgada el jueves 26 de enero del 2006. Ver también, La República, La ley que favoreció a Odebrecht y otras brasileñas fue “conversada” con Toledo, Perú, publicada el 27 de enero del 2017. https://larepublica.pe/politica/1010607-la-leyque-favorecio-a-odebrecht-y-otras-brasilenas-fue-conversada-con-toledo
} 
Como se vio líneas arriba, el financiamiento electoral era clave para Odebrecht, porque comprometía al político a retribuir el beneficio económico dado a través de beneficios en la legislación, sentando así las bases para armar la red de corrupción. Por ello, cuando realizaron aportes a la campaña de García en el 2006, la normativa de financiamiento político tampoco era lo suficientemente clara como para frenar la corrupción. De hecho, son flexibles debido a sus porosidades legales, las cuales son aprovechadas.

Por ejemplo, en el 2003, se promulgó la Ley 28094, o Ley de Partidos Políticos, la cual intentaba regular el financiamiento político. Dicha legislación fue aprovechada para facilitar la corrupción, pues la ley contiene vacíos legales, que pudieron haber sido aprovechados por los partidos políticos y por Odebrecht para operar sin presiones institucionales. Un ejemplo de tales vacíos es el artículo 31 de la ley en mención, ya que establece que los candidatos pueden recibir aportes directos, incluso de fuentes anónimas, para el financiamiento de las campañas (Tuesta: 457). Estas porosidades legales pueden terminar siendo peligrosas para el proceso, porque pueden ser aprovechadas por partidos políticos y empresas privadas que ocultan sus aportes, comprometiendo el interés público.

En efecto, cuando Marcelo apoyaba a todos los candidatos presidenciales del Perú lo hacía ilegalmente, porque eran aportes no declarados a fin de evitar sospechas si llegaban al poder para ganar licitaciones; declarando lo siguiente: "Lo que me informaron es que en Perú no era un delito hacer donaciones no contabilizadas. [...] Sé que en algunos países se podían hacer donaciones de empresas extranjeras, en otros no. [...] y la mayoría de veces los pagos eran hechos por nuestros socios [en referencia a la Caja 2]" (IDL-Reporteros 2018). En consecuencia, entidades, como la Gerencia de Supervisión de Fondos Partidarios de la ONPE (que se encargaba de detectar fondos ilícitos) no son capaces de cumplir sus funciones, porque es "dinero bajo la mesa" invisible a ellos por porosidades legales, que facilitan la corrupción.

En esa línea, por ende, entre muchos artículos como el $31^{\circ}$ de la presente ley sobre aportes no declarados de origen prohibido, no son posibles realizar su enforcement en momentos electorales, porque no disponen de recursos normativos, técnicos, inteligencia financiera entre otros mecanismos sofisticados para prevenir, controlar y sancionar la corrupción, que cada vez utilizan formas creativas, como "aportes fantasmas" o "pitufeos".

Asimismo, sobre financiamiento, la Ley 28094 tampoco fortalece a los partidos políticos, por el contrario, los vulnera frente al dinero de las corporaciones, porque estos al no recibir financiamiento estatal se vuelven vulnerables a dinero mal habido, el cual a menudo se declara bajo la modalidad del "pitufeo"27. Es decirque existe un patrón en el que aquellos que más aportan, suelen recibir algún tipo de beneficio una vez que el candidato asume el gobierno, ocultando sus aportes a fin de evitar sospechas por parte de entidades encargadas de la luchar contra la corrupción.

En consecuencia, hay una serie de incongruencias entre los partidos políticos y sus supuestas formas de financiamiento, porque en sus informes oficiales entregados a la

27 No hubo financiamiento público (solo en el papel) para las elecciones del 2006, y los partidos políticos sin organización, sin cohesión interna, sin recursos son vulnerables al dinero mal habido de grupos de interés o corporaciones. Ver también, Tuesta Soldevilla, Fernando, "Representación política: partidos por la mitad”, en Partidos políticos y elecciones: representación política en América Latina, Lima, Perú, PUCP, pp. 252-254. 
ONPE, aparecen personas que niegan haber aportado o dicen haber dado menos dinero del registrado. Incluso, usan beneficiarios de programas sociales destinados a familias en extrema pobreza que, sin embargo, aparecen como aportantes a campañas (Ojo Público 2016).

Por ejemplo, según investigaciones, más de 5 mil beneficiarios de los programas sociales Juntos y Pensión 65 aparecen como financistas del APRA en la campaña del 2006. Es decir, la forma en que se financió genera suspicacias, ya que estos aportantes estaban focalizados en programas destinados a personas en pobreza extrema. Esta evidencia permite concluir que se podría tratar de una práctica de "pitufeo" para ocultar dinero de corporaciones, como Odebrecht (2016). Asimismo, muestran que durante la campaña que llevó a Alan García a la presidencia, el partido registró aportes por más de 172 mil soles procedente de 157 deudores del estado por delitos de corrupción ${ }^{28}$.

Por esa razón, "hecha la ley, hecha la trampa"; y partidos, como el APRA, pueden aprovechar estos vacíos normativos, ocultando sus aportes y dividiéndolos, porque mientras que partidos políticos, como Alianza Para el Progreso, que dependen de grandes cantidades; el APRA depende de aportes en pequeñas cantidades, declarando que el 99\% de sus ingresos provienen de aportes entre 1 y 10 soles, que como se vio líneas arriba, pueden pertenecer a personas en situación de pobreza extrema (Fondos de Papel y Ojo Público 2016) Es decir, se puede tratar de dinero al menudeo, cuya intención es ocultar aportes de grandes corporaciones, como Odebrecht.

De esa manera, sin una norma que los fortalezca, los partidos políticos, que deberían ser actores claves, solo son actores vulnerables frente al dinero de las corporaciones, las cuales influyen para obtener vastos beneficios como, por ejemplo, ganar licitaciones para obras que luego incrementen intempestivamente sus costos, repartirse las ganancias y expandir sus negocios. Entonces, cuando llegan al poder los partidos políticos representan solo los intereses de aquellos que financiaron sus campañas, que suelen ser grupos de interés, que buscan obtener beneficios (“quid pro quo"), cuando deberían de representar a todos los ciudadanos, poniendo en peligro a la democracia (Rodríguez 8486).

En resumen, Odebrecht pudo influir para ganar la licitación del Metro de Lima línea 1 por tres razones. En primer lugar, su entrega oportuna era atractiva para García, porque podían terminar la obra antes de que acabe su mandato, incluso si es necesario hacer “arreglos baja la mesa” a fin de culminar la obra, que era símbolo de ineficacia de su anterior Gobierno (16 meses en construir). En segundo lugar, influyeron en el Estado para ganar la adjudicación del Metro, porque crearon una red de corrupción con las esferas más altas del Gobierno aprista en tres niveles (decisores, intermediarios y ejecutores) y armaron una alianza con Graña y Montero, la constructora más influyente del país, ganando la licitación del Tramo 1 y 2 del Metro de Lima. En especial, el financiamiento electoral fue clave, porque creaba una deuda a futuro, la que comprometía a García para apoyar a la constructora, a la vez que sirvió para crear las bases de una relación colusiva entre "jefes". Finalmente, en tercer lugar, la debilidad institucional fue aprovechada por la constructora, porque había un contexto normativo

\footnotetext{
28 La transparencia no es un valor en los partidos políticos peruanos, quienes suelen sacar la vuelta a la ley con prácticas ilícitas. Ver también, Ojo Público, Candidatos y millones: dinero, poder y mentiras, Perú, publicado en Fondos de Papel publicado en mayo del $2016 . \quad$ https://fondosdepapel.ojopublico.com/campanas-presidenciales/
} 
de leyes "sastres" que no solo evitaban fiscalizaciones o rendiciones de cuentas, sino que facilitaba la corrupción, como si las leyes fuesen hechas a las medidas de la corrupción, o resumido en una frase muy común: "hecha la ley, hecha la trampa”.

\subsection{REFINERÍA MIGUEL HIDALGO TULA I- MÉXICO}

El 23 de diciembre del 2016 en una Corte de Estados Unidos, ejecutivos de Odebrecht confesaron que pagaron sobornos por 10.5 millones de dólares a funcionarios mexicanos a cambio de obtener beneficios indebidos entre 2010 y $2014^{29}$. Una obra involucrada fue la Refinería Miguel Hidalgo Tula I, la cual fue ejecutada por Odebrecht en un ambiente de irregularidades durante el Gobierno priista de Peña Nieto.

Asimismo, el 15 de febrero del 2014, Braskem, una empresa offshore de Odebrecht, ganó la licitación de la Refinería Miguel Hidalgo I para el acondicionamiento, movimiento y aprovechamiento de residuales del presente proyecto. Sin embargo, según investigaciones, funcionarios de PEMEX asignaron de manera directa a la constructora brasileña que coinciden con pagos de sobornos, y un presupuesto inflado artificialmente, que representaba un sobrecosto de $61 \%$ respecto al presupuesto original, se elevó a 2 mil 315 millones de pesos, es decir, una adjudicación arreglada con sobrecostos ( MCCI 2017).

En esa línea, resumido el contexto mexicano, estamos ante un problema tan grave como complejo; que no solo se trata de escándalos y sobrecostos en obras, sino que detrás hay un sistema que facilita la corrupción. Por ello, se pretende explicar por qué Odebrecht influyó en el Estado mexicano para adjudicarse la Refinería Miguel Hidalgo Tula I.

En primer lugar, un factor clave que influyó en la adjudicación fue su entrega oportuna, que, de hecho, era atractivo para Peña Nieto por el contexto político que se manejaba, porque podían terminarla antes de que acabe su mandato (2012-2018), y que se había convertido en una prioridad para su Gobierno por la reforma energética que estaban impulsando ${ }^{30}$. Es decir, Odebrecht podía entregar la obra a tiempo a fin de inaugurarla durante su gobierno permitiéndole dar avances a su promesa política de mejorar la industria petrolera para los mexicanos, que empezaba a ser materia de crítica, incluso símbolo de fracaso durante su gestión (Expansión, 2013)

\footnotetext{
29 A pesar de los escándalos, las autoridades mexicanas no se han inmutado sobre el caso Lava Jato, parece ser que prefieren el silencio para evitar escándalos en la opinión pública. Ver, MCCI, Investigaciones de Lava Jato en 13 países, Ciudad de México. publicado el 26 de julio del 2017. https://contralacorrupcion.mx/investigacioneslavajato/

30 La reforma energética era una iniciativa de Peña Nieto para aumentar el crecimiento económico con la modernización del sector petrolero, pero algunos grupos de izquierda empezaban a cuestionarla. Ver, Expansión, Reforma energética abre debate en México, publicado el 19 de junio del 2013. https://expansion.mx/economia/2013/06/19/reforma-energetica-abre-debate-en-mexico
} 
Por ello, entre el 2011 y 2012, el Gobierno Federal publica la construcción de la Refinería Bicentenario en Hidalgo en su programa plurianual de inversiones prioritarias, como necesidad pública. Este sería un proyecto impulsado por el expresidente Felipe Calderón en el 2009 y que Peña Nieto lo reemplazaría por la modernización de una refinería ya existente en el Estado de Hidalgo durante el 2014 (Olmos 2018).

No obstante, hubo acuerdos preestablecidos para coordinar las condiciones de la obra entre dos personajes. Por un lado, estaba Luis Meneses Weyll, director de Odebrecht en México, y, por otro lado, Emilio Lozoya, ex director de Pemex, a quién le comentó que estaban interesados obtener la licitación de ese proyecto de gran magnitud, no obstante su acuerdo fue bajo ciertas condiciones; declarando lo siguiente:

"Cuando el gobierno anunció en el último trimestre del 2013, que invertiría en la ampliación de una refinería ya existente. Entonces todo lo que habíamos planeado para la nueva refinería Bicentenario, sirvió para elaborar el proyecto de la ampliación de la refinería ya existente en Tula (...) entonces le pedí su apoyo para que nosotros pudiéramos ganarlo [a Lozoya] (...) Entonces él fue muy claro al indicarme que teníamos que cumplir con los requisitos técnicos, administrativos y comerciales para que pudiéramos posicionarnos [como una empresa calificada responsable de cumplir el "pacto"] (...) y él buscaría operar y respaldar a nivel de consejo de la administración, que son los que toman la decisión final [sic]" (Quinto Elemento Lab 5 de diciembre del 2017).

Entonces, cabe precisar que una condición en la adjudicación era su eficiencia en negocios, porque implicaba ser responsable con la entrega oportuna de la obra. Es decir, era como un "me das la obra y te lo cumplo", porque con su trayectoria empresarial, que la convirtió en la mejor constructora de América Latina, podían entregar la Refinería Miguel Hidalgo, un titánico proyecto que arrastraba años de espera para inaugurarla, y, por ende, dar avances a su promesa política de modernizar el sector petrolero mexicano.

Por esa razón, desde la licitación en el 2014 hasta la inauguración, Odebrecht terminó la primera ampliación de la Refinería Miguel Hidalgo Tula el 3 de marzo del 2017 a fin de presentarla con una alta presencia pública y medios de comunicación, les tomó casi tres años construir esta mega obra para presentarla públicamente ${ }^{31}$. En consecuencia, Peña Nieto inauguró la torre fraccionadora de la planta de coque, que era parte de la reconfiguración de la refinería, a fin de que PEMEX sea una empresa más competitiva, eficiente y moderna, que era parte de su flamante reforma energética (Martínez 2017). En consecuencia, el mismo día en la inauguración, el expresidente priista declararía lo siguiente: "Con esta planta, hay una gran contribución al desarrollo nacional, y a todas y todos los mexicanos (...) A partir de la reforma energética que se está implementando (...) está haciendo que PEMEX sea una empresa más productiva, más eficiente y que pueda competir con cualquier empresa del mundo (...) y que estamos orgullosos de esta gran empresa nacional” (Presidente Enrique Peña Nieto 2017). En otras palabras, gracias a la entrega oportuna de Odebrecht, inaugurar la obra significó dar avances a la reforma energética que él estaba impulsando.

31 El 03 de marzo del 2017, Peña inaugura la torre fraccionadora de coquización, que era parte de la reconfiguración de la refinería. Ver, Martínez, Miguel Ángel, Inaugural Peña planta coquizadora de 2,600 mdd en refinería de Hidalgo, publicado por la Agencia Quadratin el 03 de noviembre del 2017. https://hidalgo.quadratin.com.mx/principal/inaugurapena-planta-coquizadora-2600-mdd-refineria-hidalgol 
De este modo, Odebrecht pudo “influir” para adjudicarse la Refinería Miguel Hidalgo Tula I, porque contaban con la capacidad tecnológica, soporte financiero, trayectoria empresarial, experiencia y eficacia para entregar la obra (casi 3 años) antes de que acabe el mandato de Peña Nieto. De tal manera con la inauguración, este dio avances a su promesa de reforma energética para los mexicanos, la cual era prioridad durante su Gobierno.

En segundo lugar, otro factor clave fue su influencia en el Gobierno, porque crearon una red de corrupción con las esferas más altas de la administración de Petróleos Mexicanos (PEMEX), relaciones colusivas con una constructora hidalguense muy influyente como CITAPIA, a partir del financiamiento político en las Elecciones Federales del 2012, en las cuales ganó Enrique Peña Nieto.

El financiamiento electoral de Odebrecht era clave para mantener relaciones a largo plazo, porque comprometían al político, o a su entorno más cercano, para obtener ventajas en contrataciones públicas. En esa línea, para este caso, el hombre clave fue Emilio Lozoya, quien entonces se desempeñaba como director de asuntos internacionales del candidato priista. En efecto, según investigaciones, Braskem, la filial petroquímica de Odebrecht, acompañó “de tiempo completo” a la campaña presidencial de Enrique Peña Nieto durante el 2012 a través de Lozoya ${ }^{32}$. Según Carlos Fadigas, director de Braskem, transfirieron sobornos a una empresa ligada a él, declarando lo siguiente:

“Acompañamos de tiempo completo toda la campaña del PRI, del Partido Revolucionario Institucional (PRI), y del actual presidente Enrique Peña Nieto. No sólo de él, sino también de su equipo (en referencia a Emilio Lozoya)”, expresó Fadigas en una reunión privada con inversionistas realizada en febrero de 2013 (MCCI 22 de octubre del 2017)

Asimismo, Luis Meneses Weyll, quien se desempeñaba como director de Odebrecht en México, acompañó a la campaña del PRI y su trato habría sido con Emilio Lozoya, a quién habría transferido 4 millones de dólares, según investigaciones:

“A principios del 2012, constaté que Emilio Lozoya había conseguido una posición destacada en el principal partido de oposición en el país (el PRI), que disputaba las elecciones presidenciales de julio del 2012 y cuyo candidato era el favorito en las encuestas[en referencia a Peña Nieto] (...) decidí invertir y materializar en algo que venía ocurriendo en los últimos años (financiar campañas), principalmente para posicionarnos ante una eventual victoria, $y$ ante un eventual posicionamiento de él en el futuro Gobierno, y fue una apuesta que hicimos (...) Le dije que estaríamos de acuerdo en contribuir con cuatro millones (..) Él estuvo de acuerdo y no puso ninguna objeción”, expresó ante la justicia brasileña (Quinto Elemento Lab 2017 en base a documentos del caso Lava Jato).

32 Braskem, la filial petroquímica de Odebrecht, acompaño a la campaña del PRI en el 2012, a través del director de asuntos internacionales, Emilio Lozoya. Ver, MCCl, Filial de Odebrecht acompañó 'de tiempo completo' campaña de Peña Nieto, Ciudad de México, publicado el 22 de octubre del 2017 
Según investigaciones de MCCI, la firma petroquímica Braskem, filial de Odebrecht, intervino durante los días de la campaña presidencial con tres transferencias por 1.5 millones de dólares a la empresa Latin America Asia Capital, ligada a Emilio Lozoya, tal como los revelan los siguientes documentos:

Entonces, como se expuso líneas arriba, Odebrecht solía invertir en las campañas para después conseguir contratos gubernamentales, porque el financiamiento electoral, como cualquier otra empresa que aporta, endeuda al político en el nivel más alto de la red, entre jefes. En este caso, apostaron por Lozoya, porque no solo se había convertido en uno de los líderes del comité de campaña, sino que probablemente se convertiría en una persona muy influyente en la administración pública de México, quién sería tiempo después director de PEMEX, empresa estatal responsable de quién ganaría la licitación de la refinería.

Cuando el PRI asumió el gobierno, y se confirmó a Emilio Lozoya como director de Petróleos Mexicanos, entre 2013 y 2014, los sobornos de Odebrecht de 5 millones de dólares a nombre de una empresa offshore Zecapan SA, que estaba ligada al entonces director de la petrolera, coincidieron con fechas claves para la adjudicación de la Refinería Miguel Hidalgo Tula 1, tal como lo revelan las investigaciones de MCCI en la siguiente cronología:

\section{Imagen 3: Adjudicación millonaria coinciden con fechas de sobornos: Cronología de hechos}

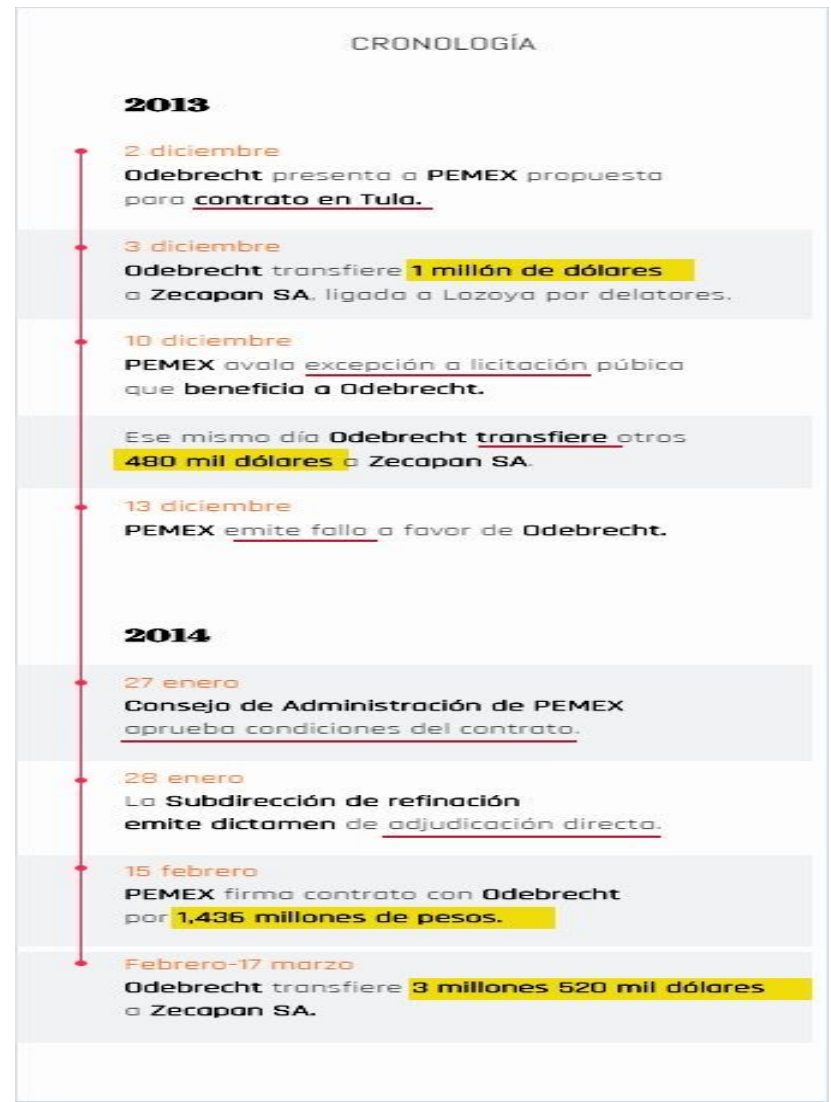

Fuente Convoca/ Raúl Olmos - MCCI el 18 mayo del 2018 
Una fecha clave fue el 27 de enero del 2014, porque el Consejo de Administración de PEMEX, que presidía Lozoya, tomó el acuerdo CAPR-004/2014 ${ }^{33}$ donde se simularía una competencia para asignar sin licitación a la firma brasileña, es decir, Odebrecht sería el único licitante. De hecho, al día siguiente, la subdirección de proyectos del área de refinación, a cargo de Jesús Lozano Peña, un hombre de confianza del entonces director, elaboró un dictamen de adjudicación directa para otorgar a Odebrecht la Refinería Miguel Hidalgo Tula I (Raúl Olmos 2018). De esa manera, el contrato sería firmado 15 de febrero de ese mismo año, donde Odebrecht ganaría arbitrariamente la modernización de la refinería.

Asimismo, otro mecanismo para considerar en el proceso es la relación colusiva que mantuvo con una influyente constructora local: CITAPIA. Según investigaciones de MCCI, para ejecutar la obra, Odebrecht contrato a tres constructoras locales, las cuales eran empresas recurrentes del entonces Secretario de Gobernación, Osorio Chong: Construcciones Sky Universal, Grupo Constructor Tulancingo y CITAPIA. En especial, esta última fue clave para el entonces director de Odebrecht en México, Luis Meneses Weyll, porque fue una empresa recomendada por Emilio Lozoya para obtener contratos, declarando lo siguiente:

"Y le indique a él (Lozoya) que la asociación que habíamos comenzado en 2011 con Tapia (dueño de la constructora) por su recomendación estaba en buen camino, que habíamos consolidado varios planes, y que nuestra prioridad sería ganar contratos”, confesó ante la justicia brasileña ( Quinto Elemento Lab 2017).

Esta constructora no solo fue importante porque tenía influencia en el Estado de Hidalgo, donde se desarrollaba la obra, sino que a su vez tenía influencia en los tres niveles de Gobierno, incluso eran los favoritos de PEMEX, porque habían logrado cuantiosos contratos con ellos; y de Osorio Chong, ex secretario de Gobernación, ex gobernador del Estado hidalguense y hombre de confianza de Enrique Peña Nieto (Aristegui 2017). Es decir, eran muy influyentes en la política y en la administración pública mexicana ${ }^{34}$; y, por ese motivo, Meneses Weyll comenta que "el dueño de CITAPIA, Juan Carlos Tapia, que era de la ciudad hidalguense de Tula, transitaban entre todo el espectro político y en las tres esferas de gobierno, siendo capaz de conquistar la millonaria obra que se avecinaba” (MCCI 2017). Es decir, era una constructora muy influyente y de una larga trayectoria con PEMEX ${ }^{35}$.

No obstante, el modelo de influencias de Odebrecht tenía como finalidad llegar a lo más alto de las relaciones entre jefes: hasta el presidente. En ese sentido, hay denuncias sobre una relación colusiva entre Enrique Peña Nieto y Marcelo Odebrecht, es decir, al nivel máximo de jefes. Según el periodista Raúl Olmos, las investigaciones deben llegar a fondo, incluso si involucran al presidente, porque MCCI reveló que hubo hasta cuatro

\footnotetext{
33 Pemex reservó cualquier documento sobre la asignación directa del contrato de esta refinería a Odebrecht hasta el 2021, con el argumento de que forma parte de las investigaciones que realiza la PGR.

34 CITAPIA, la empresa que Lozoya, recomendó a Odebrecht, había logrado cuantiosos contratos con PEMEX de 72 millones de dólares entre 2012 y 2015. Ver, Aristegui Noticias, Los negocios de CITAPIA con Pemex, el socio que Lozoya "recomendó" a Odebrecht, México, publicado el 16 de agosto del 2017. https:///aristeguinoticias.com/1608/mexico/los-negocios-de-citapiacon-pemex-el-socio-que-lozoya-recomendo-a-odebrecht

35 Osorio Chong, ex gobernador de Hidalgo y secretario de Gobernación, es uno de los personajes involucrados en esta trama por su estrecha relación con CITAPIA, Odebrecht y con la refinería. Ver MCCl, El casero de Osorio Chong gana contratos con Odebrecht, Ciudad de México, publicado el 4 de noviembre del 2017. https://contralacorrupcion.mx/odebrecht-osoriochong/
} 
reuniones previas entre los jefes ( 2018) ${ }^{36}$. Una de ellas fue en la ciudad de Querétaro el 12 de noviembre de 2012 cuando asumió la presidencia, y otra fue a través de un intermediario de Marcelo, Carlos Fadigas, quien comentó lo siguiente: "Ya hemos tenido conversaciones con el gobierno de México, no sólo con el presidente Enrique Peña Nieto, también con Emilio Lozoya, actual presidente de PEMEX, y me parece que la dirección en la que quieren ir, es muy coherente con la campaña” ( Raúl Olmos 2018 y MCCI 2017).

En breve, sobre capacidad de influencia, Odebrecht se adjudicó la Refinería Miguel Hidalgo Tula I, porque crearon una red de corrupción con las esferas más alta de administración de PEMEX, encargada de la licitación, y con una constructora local influyente como CITAPIA. En especial, el financiamiento electoral del 2012 fue clave, porque no solo creó las bases para generar la red de corrupción, sino que "endeudaban" a Lozoya para después ganar contratos gubernamentales, incluso esta red pudo haber llegado hasta el nivel más alto de jefes: Enrique Peña Nieto. En todo caso, sería materia de discusión para que las autoridades judiciales mexicanas lleven las investigaciones a fondo, o como afirma el periodista mexicano Raúl Olmos: las investigaciones implican llegar la presidente.

Finalmente, en tercer lugar, otro factor clave fue la debilidad institucional, porque Odebrecht aprovechó un contexto de instituciones sin autonomía que facilitaba la corrupción. De esa manera, instituciones encargadas de luchar contra la corrupción, como la Procuraduría General de la República (PGR), no pueden garantizar su labor, porque no tiene las condiciones necesarias para realizar sus funciones con imparcialidad.

Por ejemplo, según la Dr. María Amparo Casar, la PGR nunca ha sido una institución autónoma e independiente ni en la Constitución, ni en la práctica, porque ha sido una institución en manos y al servicio del Poder Ejecutivo, permitiendo que siga la impunidad y que los políticos se encubran mutuamente. (MCCI 2017 en la Consulta Nacional de modelo de Procuración)

Entonces, para conseguir contrataciones gubernamentales, no es coincidencia que Odebrecht arme una red de corrupción con altas esferas del Gobierno mexicano, porque una institución sin autonomía, que se encarga de la supervisión y la rendición de cuentas, se convierte en una institución que realiza parcialmente sus funciones con influencia, interna y externa, y desde arriba en la lucha contra la corrupción (PGR 2017:29-30).

A diferencia de Perú, México es uno de los países con mayor financiamiento público en América Latina a sus partidos políticos desde el 1997 hasta la actualidad; es decir, aporta fuertes cantidades de dinero estatal para sus gastos en campaña, lo que supone protegerlos de clientelismo electoral con empresas privadas. Por ello, en las Elecciones

36 De acuerdo a investigaciones periodísticas, hubo hasta cuatro reuniones entre Peña Nieto y Marcelo Odebrecht, y que sus influencias no se limitaron a PEMEX, al Gobierno Federal, sino también a líderes de otros partidos políticos.Ver, MCCl, Filial de Odebrecht acompañó 'de tiempo completo' campaña de Peña Nieto, Ciudad de México, publicado el 22 de octubre del 2017. Ver también, Olmos, Raúl, Gigante de lodo: Odebrecht y su historia de corrupción en México, Ciudad de México, Grijalbo, 2018. 
Federales del 2012, se asignaron casi 2 mil millones de dólares a los partidos políticos en sus actividades de campaña, tal como lo revela el siguiente gráfico:

\section{Gráfico 6: Financiamiento público de los partidos políticos en México otorgados por IFE-INE para gastos ordinarios y campañas}

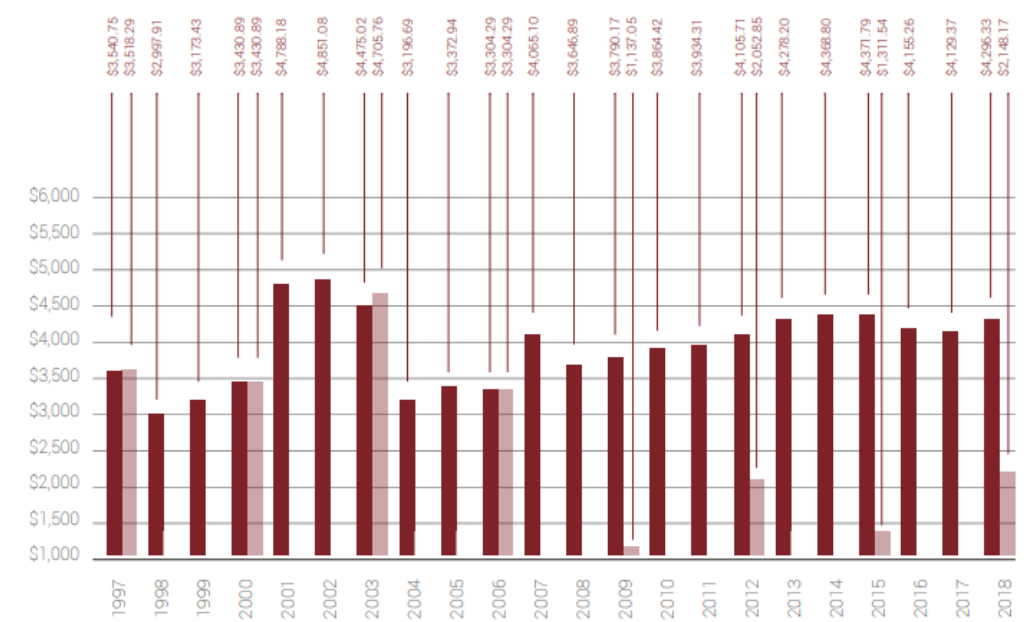

Fuente: IFE-INE en Amparo Casar y Ugalde en "Dinero bajo la mesa: financiamiento ilegal y gasto de campañas políticas en México-primera edición mayo del 2018.

Sin embargo, curiosamente, el financiamiento público es insuficiente para combatir el fondeo ilegal de las campañas. De hecho, en las elecciones del mismo año, hubo una baja fiscalización para sancionar los aportes ilegales de Odebrecht a la campaña priista, porque aunque México cuenta con uno de los sistemas más complejos del mundo en la materia, legislaciones contra la corrupción como el LEGIPE, o entidades públicas como el Instituto Federal Electoral (IFE hoy INE) con frecuencia carecen de la infraestructura, inteligencia financiera y autonomía para detectar el flujo total del dinero que fluyen a las campañas y los gastos que se realizan. (Amparo y Ugalde 2018). Es decir, las entidades electorales mexicanas pueden ser capaces de lo que reportan los partidos, pero buena parte de lo que ocurre en las campañas es dinero no declarado, por tanto invisible para sus capacidades fiscalizadoras y al “enforcement” de sus leyes electorales.

En consecuencia, el Instituto Federal Electoral (IFE hoy INE) no pueden garantizar el cumplimiento de la eficacia y transparencia en materia administrativa del artículo 77, numeral 2 inciso f y g del COFIPE sobre financiamiento de partidos políticos que los fortalece técnicamente, permitiendo aportes de personas extranjeras y empresas de carácter mercantil (2018). Es decir, a pesar de tener grandes cantidades de financiamiento público, dotaciones normativas y técnicas, entidades encargadas de luchar contra la corrupción se ven superadas con mecanismos cada vez más sofisticados ante su control fiscalizador, porque partidos como el PRI reciben dinero ilegal de empresas como Odebrecht a través de miembros de sus comités de campañas con mecanismos que parecen invisibles a la fiscalización.

En suma, Odebrecht influyó para adjudicarse la Refinería Miguel Hidalgo Tula I por tres razones. En primer lugar, su entrega oportuna era atractiva para Peña Nieto, porque con 
su soporte financiero, trayectoria empresarial y eficacia entregaron una ampliación de la obra (casi 3 años) antes de que acabe su mandato, y con la inauguración, dar avances a su promesa de reforma energética, que era prioridad durante su Gobierno. En segundo lugar, crearon una red de influencias con las esferas más alta del Gobierno Federal, de la administración de PEMEX, encargada de la licitación directa, a partir de financiamiento de campañas, sobornos y armar una alianza estratégica con CITAPIA, influyente constructora hidalguense. En especial, el financiamiento electoral del 2012 fue clave, porque no solo creaban las bases para armar la red de corrupción en el Gobierno priista, sino que comprometían a Lozoya para luego obtener licitaciones para obras públicas, incluso pudo haber llegado hasta el nivel más alto de jefes: el presidente Enrique Peña Nieto. Finalmente, en tercer lugar, aprovecharon un contexto de debilidad institucional que no solo evitaba la fiscalizaciones o rendición de cuentas, sino que facilitaba la corrupción, porque había entidades públicas que carecían de autonomía para ejercer sus funciones (PGR), o entidades electorales que carecen de inteligencia financiera (IFE) para detectar el dinero “debajo de la mesa” de Odebrecht, que son invisibles para sus capacidades fiscalizadoras para prevenir, controlar y sancionar la corrupción.

\section{Conclusiones}

El problema no solo se trata de corrupción, porque este es consecuencia de todo un sistema, que usa mecanismos legales, ilegales y antiéticos que facilitan la captura corporativa estatal, donde hay un acuerdo pre establecido entre Odebrecht y los líderes políticos para influir ventajosamente en sus países a cambio de privilegios. Sin embargo, el problema de la captura no se trata de cuestiones ideológicas, o peor aún como se afirma, por el capitalismo, sino que la preocupación tiene que ver con las reglas de juegoy sus jugadores (el que da, el que recibe y el que fiscaliza). En esa línea, a partir de dos megaproyectos, este artículo ha explicado tres factores de su sistema para ganar licitaciones en Perú y México: entrega oportuna, influencia en el Estado y debilidad institucional.

Por un lado, en Perú, los arreglos llegaron al nivel más alto de influencias: Alan García y Marcelo Odebrecht. En esa línea, ganaron la licitación del Metro de Lima por tres razones. En primer lugar, su entrega oportuna era atractiva para García, porque podían terminar la obra antes de que acabe su mandato a fin de inaugurarla, la cual se había convertido en símbolo de ineficacia y "vergüenza” de su anterior Gobierno (lograron construirlo en tiempo record: 16 meses).

En segundo lugar, influyeron en el Estado para ganar la adjudicación, porque crearon una red de corrupción con las esferas más altas del Gobierno aprista en tres niveles (jefes, intermediarios y ejecutores) a través del financiamiento electoral, sobornos, lobbies y mantener relaciones colusivas con Graña y Montero, quienes fueron sus socios influyentes en la licitación de la obra. En especial, el financiamiento electoral era clave, porque significaba la base de ese "pacto silencioso" que comprometía a García para apoyar a la constructora a largo plazo: dinero a cambio de obras.

En tercer lugar, la debilidad institucional fue aprovechada, porque había un contexto normativo de leyes "sastres" que no solo evitaban fiscalizaciones y rendiciones de cuentas, sino que facilitaba la corrupción, como si las leyes fuesen hechas a las medidas del cliente -Odebrecht-, de modo que desafiaban exitosamente el control de entidades 
públicas (CGR, ONPE, etc), partidos políticos débiles, prensa, entre otros actores en la lucha contra la corrupción.

Por otro lado, en México, también parece que el arreglo establecido llego al nivel más alto de jefes: Marcelo y Peña Nieto. En esa línea, Odebrecht ganó la licitación de la Refinería Miguel Hidalgo Tula I por tres razones. En primer lugar, su entrega oportuna era "atractiva” para Peña Nieto, porque podían entregar una ampliación de la obra (en casi 3 años) antes de que acabe su mandato, y dar "avances" a su promesa de reforma energética, la cual no solo era prioridad durante su Gobierno, sino que empezaba a ser materia de crítica.

En segundo lugar, crearon una red de influencias con las esferas más altas del Gobierno Federal (Peña Nieto y Osorio Chong), con PEMEX ( Emilio Lozoya), encargada de la licitación directa, así como formar una alianza estratégicas con una constructora influyente en el Estado hidalguense: CITAPIA. En especial, el financiamiento electoral del 2012 fue clave, porque no solo creaban las bases para armar la red de corrupción en el Gobierno priista, sino que comprometían a Lozoya para luego obtener beneficios en obras.

En tercer lugar, aprovecharon un contexto de debilidad institucional que no solo evitaban fiscalizaciones y rendiciones de cuentas, sino que facilitaba la corrupción, porque a diferencia de Perú, el caso mexicano sin leyes "sastres" tiene mejores recursos normativos, técnicos, financiamiento público generoso, etc, pero la preocupación tiene que ver con otro asunto: un conjunto entidades públicas que carecían de autonomía para ejercer sus funciones imparcialmente como la PGR, Fiscalía, IFE-INE, quienes pueden haber sido presionados por el Ejecutivo. O como afirma, la Dr. María Amparo Casar, estaban obligados a cumplir el principio de "tapaos los unos a los otros".

Asimismo, la cuestión de la corrupción proviene tanto del Estado unitario-federal como del sector privado, porque hay un binomio perfecto de la corrupción enraizado en las estructuras centrales de la sociedad y ligada a una evolución institucional precaria, donde las empresas deben obedecer a presiones de políticos y funcionarios, o a veces es la empresa quien toma la iniciativa y diseña sus formas de influir en ella. En esa línea, a diferencia de los políticos que cambian por periodo de gobierno, los empresarios siempre están en el sistema para perfeccionarlo; a tal punto de pasar desapercibidos con sus socios, porque sus aportes no solo eran "dinero bajo la mesa”, sino que se hacían a través de intermediarios o personas de confianza, de modo que no se ven involucrados ni el político ni el empresario ni sus socios. Es decir, la corrupción proviene de ambas partes.

A modo de reflexión, el manejo de poder entre empresarios y líderes políticos se expresa en "arreglos silenciosos", usando una serie de mecanismos que varían entre lo legal, ilegal y dudoso, como sobornos, lobbys, constructoras locales y financiamiento de campañas para influir ventajosamente en sus países. En especial, el financiamiento electoral es la base de ese "pacto silencioso", porque no solo compromete al político para luego devolverle el favor (deuda a futuro), sino que los empresarios que tienen el dinero buscan más poder en la política, distorsionando la democracia: dinero que busca privilegios. Por ello, el financiamiento electoral es clave, porque crea un terreno fértil para acceder a una relación especial con una serie de personajes influyentes a fin de 
obtener beneficios particulares en contra del desarrollo colectivo. Así, es el inicio de una amistad que pone en peligro a la democracia: relaciones peligrosas entre dinero, poder y política.

Para finalizar, el caso Odebrecht es solo "la punta del iceberg" en una vieja trama, porque los empresarios y líderes políticos suelen hacer el mismo pacto desde tiempos remotos en otros grandes sectores (mineros, constructores, energéticos, grupos bancarios, etc), pero el problema de la "captura" no se trata de cuestiones ideológicas, porque pueden estar tanto en gobiernos de izquierda como de derecha. La preocupación tiene que ver con la forma en que se financia la política y sus "jugadores” (el que da, el que recibe y el que fiscaliza), que se da cuando las normas son inexistentes, están distorsionadas, o se muestran inestables para luchar contra estos comportamientos oportunistas en contra del desarrollo social. Por ello, el caso Lava Jato debe servir como inspiración para empezar una nueva era con reformas institucionales que conduzcan a un auténtico desarrollo social-económico, y mejoré la política al servicio del ciudadano. 


\section{Bibliografía}

Amparo Casar, María y Ugalde, Luis Carlos (coords.). (2018). Dinero bajo la mesa: financiamiento ilegal y gasto de campañas políticas en México. Ciudad de México, Integralia Consultores y MCCI.

Aristegui. (2017). Los negocios de CITAPIA con Pemex, el socio que Lozoya "recomendó" a Odebrecht.

Ciudad de México, publicado el 16 de agosto del 2017.

Belisario, Adriano. (2017). Los tentáculos de Odebrecht en las campañas políticas de Brasil. The Intercept y Connectas. Brasil, publicado el 23 de septiembre del 2017.

Bensa, Jessica; Campos, Milagros; Muñoz, Paula, Tanaka, Martin; y Tuesta, Fernando. (2019). Hacia la democracia del bicentenario: Comisión de Alto Nivel de la Reforma Política (CANRP). Fundación Konrad Adenauer Stiftung (KAS) en Lima-Perú. Publicado en mayo del 2019.

Bresson, Jean Cartier. (2010). Relaciones peligrosas: dinero y política en América Latina. Nueva Sociedad.

Cabral, M., \& Oliveira, R. (2017). O príncipe: Una biografia não autorizada de Marcelo Odebrecht. Sao Paulo: Astral Cultural.

Casas, Kevin y Zovatto, Daniel. (2011). Para llegar a tiempo: apuntes sobre la regulación del financiamiento político en América Latina. Ciudad de México.

Código Federal de Instituciones y Procedimientos Electorales (COFIPE). (2008). México

Córdova Vianello, Lorenzo, El financiamiento a los partidos políticos en México. En Pablo Gutiérrez y

Daniel Zovatto (coordinadores): Financiamiento de los partidos políticos en América Latina. Ciudad de México. pp. 351-368

Danos, J. E.(2017). El control de la administración pública en el Perú. En EL CONTROL DE LA ACTIVIDAD ADMINISTRATIVA. (pp. 393 - 442). BOGOTÁ. Themis .

Durand, Francisco. (2016). Cuando el poder extractivo captura el Estado: lobbies, puertas giratorias y paquetazo ambiental en Perú. Lima: OXFAM

Durand, Francisco. (2018). Decretismo y captura: un breve balance con referencia al decretismo económico. Perú: Friedrich Ebert Stiftung

Durand, Francisco. (2018). Odebrecht: La empresa que capturaba gobiernos. Lima: PUCP y OXFAM. 
El País.. (2011). Alan García dice adiós con la inauguración del Metro de Lima, España, publicado el 11 de julio.

Expansión. (2013). Reforma energética abre debate en México. Ciudad de México: publicado el 19 de junio del 2013.

Gorriti, Gustavo. (2018). La caja 2 cuenta sus secretos. Perú publicado en la revista caretas-IDL- Reporteros: publicado el jueves 03 de mayo, 2018.

Gorriti, Gustavo y Mella, Romina. (2019) Las confesiones de Miguel Atala. Perú: publicado el martes 30 de abril, 2019.

Gorriti, Gustavo y Mella, Romina (2019). El Apra, “Laque” y la Caja 2. Perú: publicado el sábado 06 de abril.

Hellman, Joel; Geraint, Jones \& KAUFMANN, Daniel (2000). Seize the State, Seize the Day: State Capture, Corruption and Influence in Transition. Washington DC: Banco Mundial. Policy Research Working Paper 2444.

IDL-Reporteros (2017) Barata relata cómo ganaron la licitación del metro de lima, Perú, 15 de octubre.

IDL-Reporteros. (2017). Testimonio de Marcelo Odebrecht. Perú, publicado el 30 de diciembre.

IDL-Reporteros. (2018). Marcelo Odebrecht: el audio completo. Perú: publicado el lunes 22 de enero.

IDL-Reporteros. (2018). Dinero para todos, Lima, cuarta entrega publicada el 15 de marzo.

IDL-Reporteros. (2019). Así habló Barata: las confesiones del ex jefe de Odebrecht desde Curitiba, Perú, publicado el sábado 04 de mayo del 2019.

Jinesta, Ernesto. (2009). Los principios constitucionales de eficacia, eficiencia y rendición de cuentas de las

Administraciones Públicas. San José: Constitución y Justicia Constitucional, Poder Judicial de Costa Rica

La República (2017) La ley que favoreció a Odebrecht y otras brasileñas fue “conversada” con Toledo, Perú, publicada el 27 de enero del 2017.

La República. (2019). Club de la construcción ya existía desde el 2001, Lima, publicada el 6 de abril.

La República. (2019). Graña y Montero admitió que pagó soborno de S/ 12.5 mllns, Perú, publicado el 07 de junio del 2019.

Ley No 28094 o Ley de Partidos Políticos (2003). Diario Oficial El Peruano. Lima, Perú, Publicada el 01 de Noviembre. 
Ley No28670. (2006). Ley que declara como necesidad pública e interés nacional diversos proyectos de inversión. Diario Oficial El Peruano, publicada el jueves 26 de enero.

Lujambio, Alonso (2007): “La fiscalización de los gastos de los partidos políticos”, en Tratado de Derecho Electoral Comparado de América Latina. México: IIDH/IFE/TRIFE/Universidad de Heidelberg/Fondo de Cultura Económica

Martínez, Miguel Ángel. (2017). Inaugura Peña planta coquizadora de 2,600 mdd en refinería de Hidalgo, publicado por la Agencia Quadratin el 03 de noviembre.

Mella, Romina.. (2017). ¿Cómo Odebrecht pacto las coimas del Metro de Lima?. Perú. IDL Reporteros, publicado el jueves 21 de septiembre

Membreño, Mario (2007). Qué se entiende por captura del Estado. Tegucigalpa: Consejo Nacional de Anticorrupción.

Mexicanos Contra la Corrupción y la Impunidad. (2017). Detectan corrupción en Tula de Odebrecht”. Ciudad de México: publicada el 15 de junio.

Mexicanos Contra la Corrupción y la Impunidad. (2017) Investigaciones de Lava Jato en 13 países, Ciudad de México. publicado el 26 de julio.

Mexicanos Contra la Corrupción y la Impunidad. (2017). Filial de Odebrecht acompañó ‘de tiempo completo’ campaña de Peña Nieto, Ciudad de México, publicado el 22 de octubre.

Mexicanos Contra la Corrupción y la Impunidad. (2017). El casero de Osorio Chong gana contratos con Odebrecht, Ciudad de México, publicado el 4 de noviembre.

Odebrecht, Norberto. (1987). Sobrevivir, crecer y perpetuar: Tecnología Empresarial Odebrecht (TEO). Salvador: Odebrecht.

Ojo Público. (2016). Candidatos y millones: dinero, poder y mentiras, Perú, publicado en Fondos de Papel publicado en mayo.

Omelyanshuk, Olesky (2001). Explaining State Capture and State Capture Mdec: The cases of Russia and Ukraine. Budapest: Central European University.

Olmos, Raúl. (2018). El gigante de lodo: Odebrecht y su historia de la corrupción en México. Ciudad de México: Grijalbo: publicada el 25 de agosto del 2018.

Olmos, Raúl. (2018). Coinciden fechas de sobornos de Odebrecht con adjudicación de contrato millonario en Pemex. En Ciudad de México: MCCI el 18 de mayo vía Convoca.

Peltzman, Sam. (1976). Toward a More General Theory of Regulation. En Journal of Law and Economics, 19, $\mathrm{N}^{\circ} 2$, pp. 211-240. 
Portal, Juan Manuel, (2018). La fiscalización superior en el marco de combate a la corrupción. ¿Cómo combatir la corrupción?, México, pp.95-118.

Presidencia Enrique Peña Nieto (2017) Montaje de la Torre Fraccionadora de la Planta de Coque”, México, emitido en directo el 3 noviembre.

Procuraduría General de la República. (2017). El informe ejecutivo 2017: Consulta Nacional sobre el Modelo de Procuración de Justicia. Ciudad de México, 13 de diciembre.

Quinto Elemento Lab. (2017) Emilio Lozoya: los videos secretos de Odebrecht - 1. Ciudad de México, publicada el 5 de diciembre.

Quiroz, Alfonso. (2013). Historia de la corrupción en el Perú. Lima: Instituto de Estudios Peruanos (IEP).

Rodriguez, Denisse. (2017). Partidos pobres, campañas ricas, en Fernando Tuesta (Editor): Perú: Elecciones 2016. Un país dividido y un resultado inesperado. Lima: Fondo Editorial de la PUCP.

Rubio, Marcial. (2017). El sistema jurídico: introducción al derecho. Lima-Perú: Fondo Editorial de la PUCP.

Stigler, George. (1971). The theory of Economic Regulation. Bell Journal of Economics and Management Science: pp. 3-21.

Tuesta Soldevilla, Fernando. (2011). El financiamiento de los partidos políticos en Perú. En Pablo Gutiérrez y Daniel Zovatto (coordinadores): Financiamiento de los partidos políticos en América Latina. Ciudad de México, IDEA International, OEA y UNAM.

Tuesta Soldevilla, Fernando. (2016). Representación política: partidos por la mitad, en Partidos políticos y elecciones: representación política en América Latina. Lima, Perú: Fondo Editorial de la PUCP, pp.

252-254.

Tuesta Soldevilla, Fernando. (2019). Con mi dinero no te metas,. En El Comercio. publicado el 27 de marzo.

Zebinden, Walter; Flavio Oliva \& Antonio Gaspar (2007). A Internacionalização da Constructora Norberto Odebrecht. Revista Ciencias Empresariales da Unipar. 